\title{
Field Test and Calibration of Neutron Coincidence Counters for High-Mass Plutonium Samples
}

\author{
H. O. Menlove \\ R. J. Dickinson* \\ I. Douglas* \\ C. Orr \\ F. J. G. Rogers**
}

G. Wells"*

R. Schenkelt

G. Smith $\dagger$

A. Fattaht†

A. Ramalhoft

\section{DE87 004769}

\section{DISCLAIMER}

\begin{abstract}
This report was prepared as an account of work sponsored by an agency of the United States Government. Neithe. the United States Governnent nor any agency thereof, nor any of their employees, makes any warranty, express or implied, or assumes any legal liability or responsibility for the accuracy, completeness, or usefulness of any information, apparatus, product, or process disclosed, or represents that its use would not infringe privately owned rights. Reference herein to any specific commercial product, process, or service by trade name, trademark, manufacturer, or otherwise does not necessarily constitute or imply its endorsemen:, recommendation, or favoring by the United States Government or any agency thereuf. The views and opinions of authors expressed herein do not necessarily state or reffect those of the United States Government or any agency thereof.
\end{abstract}

- British Nuclear Fuels PLC, Risley, Warrington, Cheshire, UNITEO KINGDOM.

- Nuclear Materials Accounting Control Team, Harwell, UNITED KINGDOM.

† EURATOM Safeguards Directorate, Commission of the European Communities, Batiment Jean Monnet, Plateau du Kirchberg, LUXEMBOURG.

$†$ International Atomic Energy Agency, Vienna, AUSTRIA. 
CONTENTS

ABSTRACT .......................... . . . . 1

I. INTRODUCTION .................. 2

II. EQUIPMENT DESCRIPTION . . . . . . . . . . . . . . . 3

A. HLNCC-II . . . . . . . . . . . . . . . 4

B. PPNCC .................. 4

C. BNFL Coincidence systen . . . . . . . . . 5

III. SAMPLE DESCRIPTION . . . . . . . . . . . . . 5

IV. EXPERIMENTAL PROCEDURE . . . . . . . . . . . . 7

V. SYSTEM COMPRRISON RESULTS . . . . . . . . . . . . . 8

A. Operating Parameters . . . . . . . . . . . . . 8

B. Experimental Data . . . . . . . . . . . 9

C. Totals Rate Ratios . . . . . . . . . 15

D. Reals Rate Ratios............. 17

E. Outliers . . . . . . . . . . . . 19

F. Garma-Ray Sensitivity . . . . . . . . . . 20

G. Samp $\perp$-Positioning Errors . . . . . . . . . 22

H. Wall-Reflection Effects . . . . . . . . . 23

VI. CALIBRATION RESULTS . . . . . . . . . . . . . 23

A. Sample-Container Correction . . . . . . . . . . 24

B. Californiur 252 Source Normalization . . . . 25

Belgonucleaire (EURATOM/Los Alamos counter) . . 25

C. Deadtime Correction . . . . . . . . . . . . 26

D. Updated Results Covering Lower Mass Range . . 26

E. EURATOM/Los Alamos Calibration Results . . . 28

F. Totals Rate Analysis . . . . . . . . . . 33

VII. MULTIPLICATION ANALYSIS ............ 36

A. Multiplication Equations . . . . . . . . 36

B. Multiplication constant . . . . . . . . . 37

C. Multiplication Consistency checks . . . . . . 38

D. Multiplication Investigation . . . . . . . 39

VIII. SUMMARY ................... . 42

ACKNOWLEDGMENTS . . . . . . . . . . . . . . . . 45

REFERENCES .........................45 
FIELD TEST AND CALIBRATION OF NEUTRON COINCIDENCE COUNTERS FOR HIGH-MASS PLUTONIUM SAMPLES

by

H. O. Menlove, R. J. Dickinson, I. Douglas,

C. Orr, F. J. G. Rogers,

G. Wells, R. Schenkel, G. Smith,

A. Fattah, and A. Ramalho

\begin{abstract}
Five different neutron coincidence systems were evaluated and calibrated for high-mass $\mathrm{PuO}_{2}$ samples. The samples were from 2 to $7.2 \mathrm{~kg}$ of $\mathrm{PuO}_{2}$ in mass, with a large range of burnup. This report compares the equipment and the results, with an evaluation of deadtime and multiplication corrections.
\end{abstract}




\section{INTRODUCTION}

During the past several years, new equipment has been developed to measure high-mass plutonium samples using neutron time-correlation (coincidence) counting. It was necessary to test this equipment and calibrate it for high-mass (2 to $7.2 \mathrm{~kg}$ ) plutonium samples. To this end, an exercise was organized at the sellafield Nuclear Facility in the United Kingdom during the week of January 14, 1985. The following organizations participated in the exercise:

$\begin{array}{ll}\text { BNEL } & \text { British Nuclear Fields, Risley, warrington, Cheshire, United } \\ & \text { Kingdom, and sellafield; } \\ \text { Nuclear Materials Accounting Control Team, Harwell, United } & \text { Kingdom; } \\ \text { EURATOM } & \text { Directorate of EURATOM Safeguards, Kirchberg, Luxembourg; } \\ \text { IAEA } & \text { International Atomic Energy Agency, Vienna, Austria; and } \\ \text { LOS Alamos } & \text { Los Alamos National Laboratory, Los Alamos, New Mexico, } \\ & \text { United states. }\end{array}$

The exercise at sellafield had two primary purposes:

- to evaluate the performance of the gamma-ray and the neutron coinc1dence detectors for plutonium assay at very high counting rates and

- to calibrate several nondestructive assay systems for $\mathrm{PuO}_{2}$ sample masses Erom 2 to $7.2 \mathrm{~kg}$.

These two goals are covered in separate sections of the report. The first section covers the topics of neutron detector comparison, deadtime, bias, geometric effects, and data consistency.

The second section covers the calibration, multiplication corrections, moisture effects, and outliers. The more detalled multiplication and calibratIon results are presented for only one of the neutron detector systems. These results are correlated with prior results obtained at Los Alamos National Laboratory and Belgonucleaire in Belgium using the same detector but covering a lower range of mass.

The high precision and consistency of the neutron detector results made it possible to isolate all outliers as "sample problems" and not "instrument 
problems." That is, all instruments identified the same three to Lviı samples as outliers, and the direction and magnitude of the discrepancies were used to help evaluate the source of the problem.

This report gives the neutron results but not the gamma-ray spectroscopy results for plutonium isotopic ratios. The preliminary gamma-ray results have been evaluated separately by EURATOM and BNFL. The plutonium isotopic ratios supplied by the facility operator were used for all of the data reduction in this report.

\section{II . EQUIPMENT DESCRIPTION}

Five neutron councers and two gamma-ray systems were used in the exercise. These seven counting systems are listed in Table $I$ and described in this section.

All of the samples were ineasured in each of the neutron systems, which provided a good check of the consistency and precision of the different systems. The sample masses and neutron counting rates were higher than had been measured previously. These high rates gave a good check on the validity of deadtime and multiplication corrections. A comparison of the detector results is given in Sec. $v$.

TABLE I

EQUIPHENT USED FOR THE PLO 2 MRASURERENTS AT SELLAFIBLD

\begin{tabular}{|c|c|c|c|c|}
\hline Item & Slgnal & Organization & Detectors & Colnc1dence Electronics \\
\hline Hex counter & Meutions & BNEL & $12-{ }^{3}$ He tubes & Computer chip \\
\hline PPNCC & Neutrons & NIACT & $18--^{3}$ He tubes & Harwell shift reglster \\
\hline HLNC-II (JCC-3I) & Neut rons & IAEA $(1)$ & $18--^{3}$ He tubes & Sh1Et register (JSR-1L) \\
\hline HLNC-II $(J C C-31)$ & Neutrons & IAEA (2) & $18--^{3}$ He tubes & Shift reqister (JSR-11) \\
\hline HLNC-II (Los Alamos) & Neutrons & EURATOM/LOS Alamos & $18--^{3}$ He tubes & Shift register (HEC-100) \\
\hline Ge (EURATOA) & Gamma rays & BURATOM & $\mathrm{Ge}$ & -- \\
\hline Ge (BNPL) & Gamma rays & BNFL & $\mathrm{Ge}$ & -- \\
\hline
\end{tabular}


The HLNCC-II* detector is a portable neutron counter developed ${ }^{l}$ for high-mass plutonium samples. A schematic diagram of the detector is shown in Fig. l, and details on the system are given in Ref. 1 . Three of these systems were used to obtain independent calibration data and to study differences between the systems and electronics. The two IAEA systems used the new commercial shift register (JSR-11) produced by JOMAR Systems** based on the Los Alamos design. These units used the AMPTEK ${ }^{\dagger}$ amplifiers (six per system) and a derandomizing buffer in the shift-register board. The older EURATOM/LOS Alamos system used an $\mathrm{IRT}^{+t}$ (HEC-100) shift register that had been modified to operate the

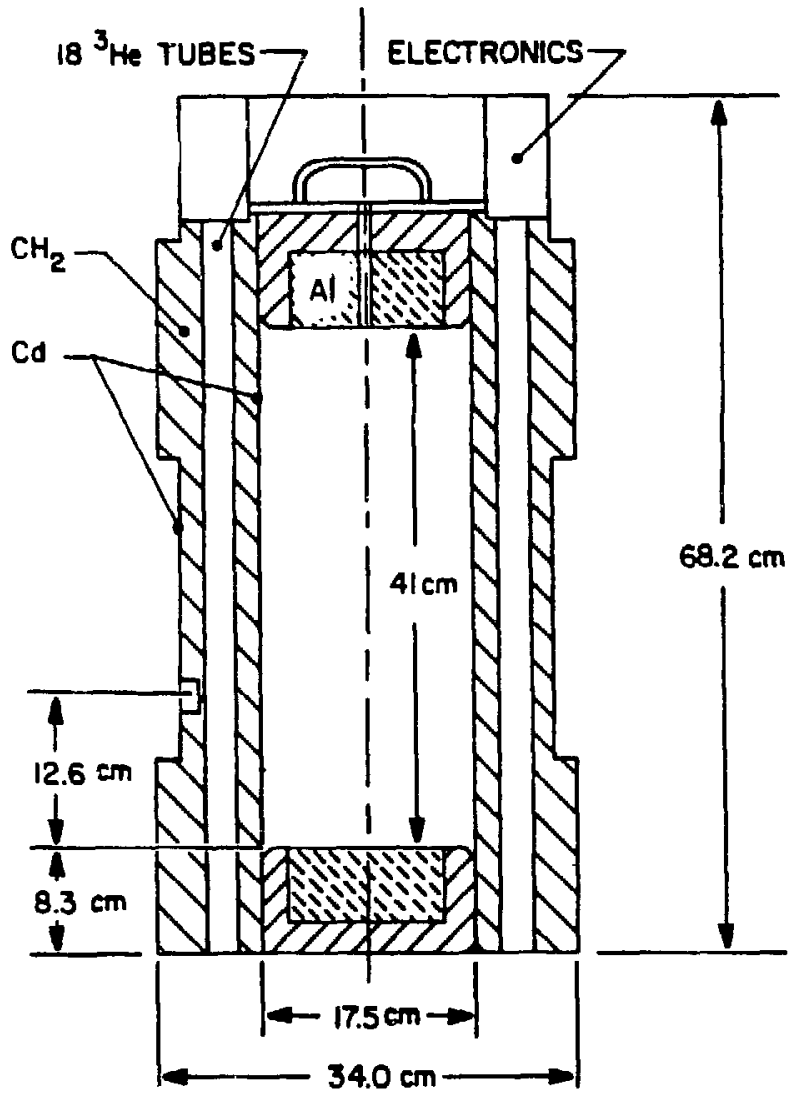

Fig. 1. Diagram of HLNC-II. AMPTEK detector head.

Each of the three systems had a Hewlett-Packard HP-85 minicomputer for data collection and analyses using the software program CAL4 (Ref. 2).

\section{B. PPNCC}

The portable passive neutron coincidence counter (PPNCC) system has been used by MMACT at Harwell for several years for the colncidence counting of bulk plutonium samples. This system is hexagonal with three ${ }^{3}$ He tubes in each side, giving a total of 18 tubes. The sample cavity is larger than that of the HLNC-II, resulting in more neutron leakage and a smaller detection efficiency. The system uses conventional preamplifiers and amplifiers (six each) developed at Harwell, and the electronic deadtime is similar to the older HLNC-I. ${ }^{3}$

\footnotetext{
*Further usage of this acronym in this report will be the IAEA four-letter code HLNC-II.

* JoMAR Systems, 1143 l8th street, Los Alamos, NM 87544.

taMPTEK, InC., 6 DeAngelo Drive, Bedford, MA 01730.

t+IRT Corp., P.O. Box 85317, San Diego, CA 92138 .
} 
The deadtime used during the sellafield exercise was found to be too small, so it was subsequently modifled 4 by Harwell staff. Only the modified data results are used in this report.

\section{BNFL Coincidence system}

The BNFL counter has a hexagonal detector head similar in size to that of the HLNC-I, but it had the following changes:

- The detector walls were thicker than those of the HLNC-I and had only two ${ }^{3}$ He tubes in each side.

- Each of the 12 detector tubes was connected to its individual preamplifier and amplifier to reduce deadtime.

- The BNFL coincidence electronics replaced the shift register with a computer chip and a fast clock. These replacements allowed more flexibility in selecting the predelay and gate width.

\section{SAMPLE DESCrIPTION}

The facility operator provided a variety of high-mass plutonium samples for the measurements. These samples covered a wide range of age since separation and 241 Am content.

Table II describes the samples. The ${ }^{240}$ Pu-effective is defined as

$$
{ }^{240} \text { Pu-effective }=2.49 \mathrm{M}_{238}+\mathrm{M}_{240}+1.57 \mathrm{M}_{242} \text {, }
$$

where $\mathrm{M}_{238}, \mathrm{M}_{240}$, and $\mathrm{M}_{242}$ are the masses of ${ }^{238} \mathrm{Pu},{ }^{240} \mathrm{Pu}$, and ${ }^{242} \mathrm{Pu}$. The parameter $\alpha$ is defined as the ratio of $(\alpha, n)$ neutrons to spontaneous-fission neutrons as calculated from the plutonium isotopics and the $(\alpha, n)$ yields from pure $\mathrm{PuO}_{2}$ (see Sec. VII.A). 
TABLB II

PUO 2 SAMPLE SPECIFICATIONS

(Updated to January 1, 1985)

\begin{tabular}{|c|c|c|c|c|c|c|c|c|c|c|c|}
\hline $\begin{array}{l}\text { Sample } \\
\text { No. }\end{array}$ & $\begin{array}{l}\text { Pu } \\
\text { (q) }\end{array}$ & $\begin{array}{r}{ }^{238} \\
\mathrm{Pu} \\
\text { (8) } \\
\end{array}$ & $\begin{array}{l}239 \mathrm{Pu} \\
\text { (v) }\end{array}$ & $\begin{array}{l}249 \mathrm{Pu} \\
(8) \\
\end{array}$ & $\begin{array}{c}241_{\mathrm{pu}} \\
(z)\end{array}$ & $\begin{array}{c}242_{\mathrm{Pu}} \\
(8) \\
\end{array}$ & $\begin{array}{l}24.1 \\
\text { SEp }\end{array}$ & & $\begin{array}{l}240_{\mathrm{Pu}-\mathrm{eff} .} \\
\mathrm{(g)}\end{array}$ & $a$ & $\begin{array}{c}239+241 \\
\text { (a) }\end{array}$ \\
\hline 1 & 7156.5 & 0.188 & 72.09 & 22.87 & 3.91 & 0.943 & & 978 & 1776 & 0.365 & 5439 \\
\hline 2 & 6807.4 & 0.188 & 71.22 & 23.59 & $\therefore .00$ & 1.004 & & 162 & 1745 & 0.368 & 5120 \\
\hline 3 & 6704.5 & 0.200 & 70.35 & 23.83 & 4.59 & 1.041 & & 670 & 1740 & 0.334 & 5024 \\
\hline 4 & 6531.7 & 0.118 & 73.02 & 22.45 & 3.53 & 0.874 & 50 & 057 & 1575 & 0.359 & 5000 \\
\hline 5 & 6254.6 & 0.114 & 75.80 & 20.97 & 2.49 & 0.538 & 12 & 210 & 1391.7 & 0.467 & 4897 \\
\hline 6 & 5951.9 & 0.135 & 74.78 & 21.52 & 2.84 & 0.737 & 9 & 973 & 1369 & 0.440 & 4620 \\
\hline 7 & 5753.9 & 0.124 & 75.54 & 21.05 & 2.61 & 0.678 & 11 & 680 & I 289.9 & 0.463 & 4497 \\
\hline 8 & 5647.4 & 0.133 & 75.03 & 21.47 & 2.64 & 0.729 & 12 & 496 & 1295.8 & 0.469 & 4386 \\
\hline 9 & $5 \quad 432.9$ & 0.105 & 75.01 & 21.46 & 2.69 & 0.738 & 10 & 748 & 1243 & 0.434 & 4221 \\
\hline 10 & 5332.6 & 0.113 & 76.47 & 20.62 & 2.17 & 0.628 & 12 & 817 & 1167 & 0.481 & 4194 \\
\hline 11 & 4968.4 & 0.469 & 76.65 & 17.66 & 3.71 & 1.512 & 28 & 143 & 1053 & 0.883 & 3993 \\
\hline 12 & 4768.0 & 0.113 & 75.88 & 20.96 & 2.39 & 0.658 & 12 & 813 & 1062 & 0.474 & 3732 \\
\hline 13 & 4597.6 & 0.114 & 75.57 & 21.11 & 2.56 & 0.649 & 13 & 173 & 1030 & 0.476 & 3592 \\
\hline 14 & 4488.4 & 0.122 & 76.72 & 20.34 & 2.21 & 0.608 & 12 & 845 & 969.5 & 0.492 & 3543 \\
\hline 15 & 3811.6 & 0.113 & 75.47 & 21.31 & 2.40 & 0.710 & 14 & 069 & 865.4 & 0.480 & 2968 \\
\hline 16 & 3821.8 & 0.178 & 73.12 & 22.35 & 3.51 & 0.842 & 2 & 904 & 921.5 & 0.368 & 2929 \\
\hline 17 & 2671.8 & 0.915 & 67.55 & 23.32 & 4.59 & 3.63 & 35 & 452 & 836.0 & 0.855 & 1927 \\
\hline 18 & 2541.3 & 0.946 & 66.31 & 22.90 & 6.28 & 3.57 & 47 & 630 & 784.2 & 0.979 & 1845 \\
\hline 19 & 2476.0 & 0.915 & 67.55 & 23.32 & 4.59 & 3.63 & 35 & 452 & 774.8 & 0.955 & 1786 \\
\hline
\end{tabular}

The scimples were all doubly encapsuleted in metal cans, with a polyethylene bag around the inside can. The substantial wall thickness of the cans resulted in a correction of

$\frac{T(\text { Sellafield can) }}{\text { T(negligible wall thickness) }}=1.013$

and 
These wall-thickness corrections were not made to the comparison data, but the corrections were made before doing the calibration fit for the EURATOM/Los Alamos detector. This method makes it possible to compare the results with the prior data where the wall thicknesses were negligible or corrected for.

IV. EXPERIMENTAL PROCEDURE

For the measuremerits, all of the equipment was set up in a shielded room near the storage area as shown in Fig. 2. The room had thick concrete walls with inside dimensions of $\sim 4$ by $8 \mathrm{~m}$, and the average distance between detectors was $\sim 2 \mathrm{~m}$. Each sample was counted in each detector for approximately $3 \times 200 \mathrm{~s}$, or a total of $10 \mathrm{~min}$ per system. The sample was then moved clockwise to the next detector as shown in Fig. 2. The gamma-ray counts typically took $20 \mathrm{~min}$. Only one sample was allowed in the room at a time for criticality and safety reasons. Thus, each sample required about $1.5 \mathrm{~h}$ to complete the cycle.

Normalization measurements using two different ${ }^{252} \mathrm{Cf}$ sources were made in the detectors that were not occupied by the $\mathrm{FuO}_{2}$ sample. The ${ }^{252} \mathrm{CF}$ sources were $\mathrm{D}-372$ from Los Alamos and CE-2 from Harwell. They had the following yields (based on LOS Alamos ${ }^{252}$ Cf source $C R-5$ ):

$$
\mathrm{D}-372=9.00 \times 10^{3} \mathrm{n} / \mathrm{s} \text { on } 85-02-01, \text { (year-month-day) }
$$

and

$$
\mathrm{Cf}-2=7.39 \times 10^{4} \mathrm{n} / \mathrm{s} \text { on } 85-02-01 .
$$

Room-background neutron rates were measured both with and without the $\mathrm{PuO}_{2}$ sample in the room. Essentially all of the background was from the $\mathrm{PuO}_{2}$ assay sample, so the detector containing the sample had negligible background $\left(\sim 50\right.$ counts/s) from other sources during the $\mathrm{PuO}_{2}$ assay. However, for some of 


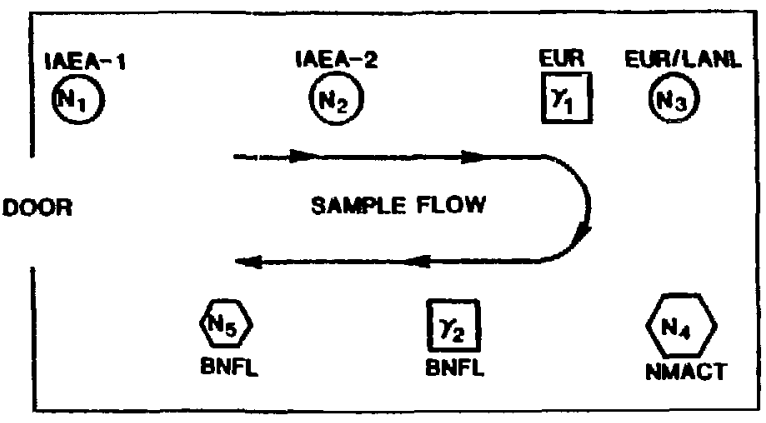

Fig. 2. Position of nondestructive assay equipment in the measurement room at sellafield.

the ${ }^{252}$ cf measurements, a significant background was induced from the large $\mathrm{PuO}_{2}$ sample in one of the neighboring detectors. The normal data reduction included an appropriate room-background subtraction.

Separate measurements were performed to determine (1) the effect of the vault-wall reflection on the neutron counting efficiency and (2) the variability in can positioning in the detector sample cavity.

Gamma-ray dose measurements were made to determine the exposure to the operators and the ${ }^{3} \mathrm{He}$ detectors. In general, the gamma dose in the tubes should not get above $\sim \mathrm{R} / \mathrm{h}$ to avold gamma-ray pileup into the neutron spectrum. This limit differs for the three types of systems. That is, the shorter amplifier time constants $(\sim 0.15 \mu s)$ in the AMPTEK-based systems (HLNC-II) give better neutron/gamma-ray discrimination. Also, the large number (12) of amplifiers on the BNFL system reduces the gamma-ray pileup problem. When gamma-ray pileup is a problem (above the neutron discrimination threshold), the observed totals rate increases and the colncidence rate decreases.

\section{SYSTEM COMPARISON RESULTS}

\section{A. Operating Parameters}

Each of the neutron systems had different operating parameters, although the three HLNC-II systems were almost identical. Table III lists the five neutron systems and their totals efficiencies, counting and predelay gates, die-away times, and deadtime coefficients.

The efficiencies were determined by a calibrated ${ }^{252}$ cf source $(\mathrm{CR}-5)^{i}$ measured at Los Alamos in IAEA-1, and the totals rate ratio of the other counters was compared with the ratio for this unit for source D-372 measured at sellafield. 
TABLE III

OPERATING PARAMETERS FOR THE NEUTRON DETECTORS

\begin{tabular}{|c|c|c|c|c|c|}
\hline Counter & $\begin{array}{l}\text { Predelay } \\
\text { (us) }\end{array}$ & $\begin{array}{l}\text { Gate } \\
\text { (us) }\end{array}$ & $\begin{array}{c}\text { otals, } \\
(8)\end{array}$ & $\begin{array}{c}\text { Coincidence Deadtime, } \\
\text { (us) }\end{array}$ & $\begin{array}{c}\text { Totals } \\
\text { Deadt1me }\end{array}$ \\
\hline & 4.5 & 64 & 18.3 & $0.68+0.22 \cdot 10^{-6} \mathrm{~T}$ & $8 / 4$ \\
\hline er) & 4.5 & 64 & 17.9 & $0.62+0.20 \cdot 10^{-6} \mathrm{~T}$ & $8 / 4$ \\
\hline Alamos (silver) & 4.5 & 64 & 17.5 & $0.68+0.22 \cdot 10^{-6} \mathrm{~T}$ & $\delta / 4$ \\
\hline & 4.5 & 32 & $\ln .5$ & $2+0+2$ & $\therefore$ \\
\hline & 4.5 & 95.94 & 11.9 & $1.38+0.58 \cdot 10^{-6} \mathrm{~T}$ & $>8 / 4.5$ \\
\hline
\end{tabular}

The deadtime coefficients were obtained for each detector system either before or after the seliafield exercise. This was done using ${ }^{252} \mathrm{cf}$ and/or AmLi sources. Because the sellafield measurements pushed the counting rates to higher than normal levels $\left(-500000 \mathrm{~s}^{-1}\right)$, checking for consistency in the deadtime coefficients between the different systems was possible. The coincidence deadtime is about Eour times larger than the totals deadtime, so an error in the deadtime shows up in the comparison of $R / T$ ratios and in the high-rate and low-rate sample ratios.

\section{B. Experimental Data}

The basic counting rates before and after multiplication corrections are listed in Tables IV-VIII. AlI of the rates have been corrected for room background (small) and deadtime using

$$
R_{c}=1 R(\text { meas }) e^{\delta T(\text { meas })}
$$

and

$$
T_{G}=T(\text { meas }) e^{\delta_{T} T(\text { meas })},
$$


TABLE IV

NEUTRON DATA SUMMARY FOR HLNC-II COUNTER IAEA-1

\begin{tabular}{|c|c|c|c|c|c|c|}
\hline Sample & $\begin{array}{c}\text { Deadtime } \\
\text { Correction (a) }\end{array}$ & $\begin{array}{c}T_{c} \\
\left(s^{-1}\right)^{(b)}\end{array}$ & $\left(s^{-1}\right)^{R_{c}}$ & $\begin{array}{c}\text { Multiple } \\
\text { Correction } \\
\mathrm{R}_{\mathrm{mc}} \\
\end{array}$ & $\frac{\mathrm{R}_{\mathrm{mc}}}{\mathrm{g}}$ & $M_{\ell}{ }^{(c)}$ \\
\hline 1 & 1.504 & $561 \quad 138$ & $102 \quad 162$ & 32529 & 18.31 & 1.302 \\
\hline 2 & 1.493 & 551788 & 99393 & 32017 & 18.35 & 1.297 \\
\hline 3 & 1.482 & 541445 & $99 \quad 177$ & 32180 & 18.49 & 1.299 \\
\hline 4 & 1.444 & $506 \quad 150$ & 90174 & 29700 & 18.86 & 1.291 \\
\hline 5 & 1.405 & 469342 & 76806 & 25879 & 18.59 & 1.273 \\
\hline 6 & 1.377 & 449219 & 70415 & 25678 & 18.76 & 1.251 \\
\hline 7 & 1.374 & 439651 & 65634 & 25037 & 18.29 & 1.236 \\
\hline 8 & 1.361 & 427097 & 65313 & 24031 & 18.54 & 1.246 \\
\hline 9 & 1.337 & 403124 & 59789 & 23562 & 18.96 & 1.229 \\
\hline 10 & 1.318 & 383376 & 55266 & 21579 & 38.49 & 1.227 \\
\hline 11 & 1.378 & 443365 & 57298 & 19650 & 18.66 & 1.234 \\
\hline 12 & 1.306 & 370803 & 48973 & 21753 & 20.48 & 1.192 \\
\hline 13 & 1.268 & 331377 & 44861 & 19259 & 18.70 & 1.201 \\
\hline 14 & 1.259 & 321649 & 44568 & 18326 & 18.90 & 1.212 \\
\hline 15 & 1.214 & $272 \quad 214$ & 34488 & 16082 & 18.58 & 1.178 \\
\hline 16 & 1.216 & $273 \quad 454$ & 40485 & 16914 & 18.35 & 1.217 \\
\hline 17 & 1.285 & $348 \quad 737$ & 34789 & 16882 & 20.19 & 1.147 \\
\hline 18 & 1.275 & 339041 & 34842 & $15 \quad 102$ & 19.26 & 1.168 \\
\hline 19 & 1.267 & 329937 & 33428 & 15907 & 20.53 & 1.152 \\
\hline
\end{tabular}

Average

18.91

Scatter (1o)

$\pm 0.71$

lo( 8$)$

$\pm 3.7$

CF $(D-372) \quad 1.001$

1624

317.9

\footnotetext{
(a) The coincidence deadtime coefficient was $\delta=\left(0.68+0.22 \mathrm{~T} \cdot 10^{-6}\right) \mathrm{\mu s}$.

(b) The data have been corrected for wall reflection by 1.015 for totals and 1.03 for reals.

(c) $\mathbf{M}_{\ell}=$ leakage nultiplication.
} 
TABLE V

NEUTRON DATA SUMMARY FOR HLNC-II COUNTER IAEA-2

\begin{tabular}{|c|c|c|c|c|c|c|}
\hline Sample & $\begin{array}{l}\text { Deadtime } \\
\text { Correction }\end{array}$ & $\begin{array}{c}\mathbf{T}_{\mathrm{c}} \\
\left(\mathrm{s}^{-1}\right) \\
\end{array}$ & $\begin{array}{c}R_{C} \\
\left(s^{-1}\right) \\
\end{array}$ & $\begin{array}{c}\text { Multiple } \\
\text { Correction } \\
\mathrm{R}_{\mathrm{mc}} \\
\end{array}$ & $\underline{\underline{\mathrm{r}}} \underline{\mathrm{g}}$ & $M_{\ell}{ }^{(b)}$ \\
\hline 1 & 1.435 & 549062 & 97864 & 32055 & 18.05 & 1.292 \\
\hline 2 & 1.426 & 539365 & 94787 & 31558 & 18.08 & 1.287 \\
\hline 3 & 1.417 & 529737 & $94 \quad 564$ & 31762 & 18.25 & 1.288 \\
\hline 4 & 1.385 & $496 \quad 389$ & 86096 & 29389 & 18.66 & 1.280 \\
\hline 5 & 1.350 & $459 \quad 164$ & $73 \quad 627$ & 25485 & 18.31 & 1.265 \\
\hline 6 & 1.335 & 441746 & 67306 & $25 \quad 484$ & 18.62 & 1.240 \\
\hline 7 & 1.325 & 430581 & 62403 & 24750 & 19.19 & 1.225 \\
\hline 8 & 1.314 & 419202 & 63049 & 23711 & 18.30 & 1.240 \\
\hline 9 & 1.293 & $395 \quad 194$ & 57576 & $23 \quad 224$ & 18.69 & 1.220 \\
\hline 10 & 1.276 & $374 \quad 938$ & 53280 & 21385 & 18.33 & 1.220 \\
\hline 11 & 1.328 & 43487 ? & 54786 & 19414 & 18.44 & 1.225 \\
\hline 12 & 1.266 & 363353 & 16958 & $21 \quad 455$ & 20.20 & 1.184 \\
\hline 13 & 1.233 & $324 \quad 105$ & 42630 & 19004 & 18.45 & 1.190 \\
\hline 14 & 1.226 & 315708 & $43 \quad 033$ & 18078 & 18.65 & 1.206 \\
\hline 15 & 1.187 & $267 \quad 028$ & 33400 & 15837 & 18.30 & 1.173 \\
\hline 16 & 1.189 & 268749 & $38 \quad 818$ & 16752 & 18.18 & 1.208 \\
\hline 17 & 1.248 & 341519 & 33530 & 16601 & 19.86 & 1.142 \\
\hline 18 & 1.240 & 332811 & 33565 & 14896 & 18.79 & 1.163 \\
\hline 19 & 1.234 & 324701 & $32 \quad 032$ & 15764 & 20.34 & 1.144 \\
\hline
\end{tabular}

Average

18.73

Scatter (lo)

$\pm 0.69$

$\operatorname{lo}(8)$

$\pm 3.7$

CE $(D-372) \quad 1.001$

1600

308.0

(a) The coincidence deadtime coefficient was $\delta=\left(0.62+0.2 \mathrm{~T} \cdot 10^{-6}\right) \mu \mathrm{s}$.

(b) ${ }_{M_{2}}=$ leakage multiplication. 
TABLE VI

NEUTRON DATA SUMAARY FOR HLNC-IT COUNTER EURATOM/LOS ALAMOS

\begin{tabular}{|c|c|c|c|c|c|c|}
\hline Sample & $\begin{array}{l}\text { Deadtime (a) } \\
\text { Correction }\end{array}$ & $\begin{array}{c}\mathbf{T}_{\mathrm{c}} \\
\left(\mathrm{s}^{-1}\right) \\
\end{array}$ & $\begin{array}{c}R_{c} \\
\left(s^{-1}\right) \\
\end{array}$ & $\begin{array}{c}\text { Multiple } \\
\text { Correction } \\
\mathrm{R}_{\mathrm{mc}} \\
\end{array}$ & $\frac{R_{\mathrm{mc}}}{\mathrm{g}}$ & $M_{l}{ }^{(b)}$ \\
\hline 1 & 1.470 & $\begin{array}{ll}538 & 267\end{array}$ & 93726 & 31670 & 17.83 & 1.282 \\
\hline 2 & 1.462 & 530964 & 92168 & 31190 & 17.87 & i. 282 \\
\hline 3 & 1.450 & 519551 & 90763 & 31373 & 18.03 & 1.278 \\
\hline 4 & 1.415 & 486152 & $82 \quad 667$ & 28971 & 18.39 & 1.271 \\
\hline 5 & 1.379 & 451564 & 72054 & $25 \quad 101$ & 18.03 & 1.263 \\
\hline 6 & 1.359 & $430 \quad 887$ & 64535 & 24989 & 18.25 & 1.234 \\
\hline 7 & 1.352 & 424253 & $61 \quad 172$ & $24 \quad 424$ & 18.93 & 1.223 \\
\hline 8 & 1.336 & 407951 & 59916 & $23 \quad 247$ & 17.94 & 1.230 \\
\hline 9 & 1.314 & 385079 & 54754 & 22807 & 18.35 & 1.213 \\
\hline 10 & 1.298 & 368076 & $51 \quad 459$ & 20914 & 17.92 & 1.215 \\
\hline 11 & 1.353 & 425209 & 52723 & 19067 & 18.11 & 1.220 \\
\hline 12 & 1.285 & $354 \quad 233$ & 44850 & 21048 & 19.82 & 1.177 \\
\hline 13 & 1.250 & 316010 & 40808 & 13630 & 18.09 & 1.184 \\
\hline 14 & 1.244 & 309202 & 41610 & 17775 & 18.33 & 1.201 \\
\hline 15 & 1.202 & 262131 & 32142 & 15637 & $i 8.07$ & 1.166 \\
\hline 16 & 1.203 & 263410 & 37669 & 16473 & 17.88 & 1.204 \\
\hline 17 & 1.265 & 332751 & 32257 & $16 \quad 229$ & 19.41 & 1.139 \\
\hline 18 & 1.259 & 326596 & 32524 & 14667 & 18.70 & 1.159 \\
\hline 19 & 1.251 & 317652 & 31214 & 15438 & 19.93 & 1.143 \\
\hline Average & & & & & 18.41 & \\
\hline scatter & $10)$ & & & & \pm 0.65 & \\
\hline $1 \sigma(z)$ & & & & & \pm 3.5 & \\
\hline Cf $\quad(D-372$ & 1.001 & 1581 & 297.7 & & & \\
\hline
\end{tabular}

(a) The coincidence deadtime coefficient was $\delta=\left(0.68+0.22 \mathrm{~T} \cdot 10^{-6}\right)$ $\mu \mathrm{s}$. (b) $M_{l}=$ leakage multiplication. 
TABLE VII

NEUTRON DATA SUMMARY FOR NMACT COUNTER PPNCC

\begin{tabular}{|c|c|c|c|c|c|c|c|c|c|}
\hline Sample & $\begin{array}{l}\text { Deadtime (a) } \\
\text { Correction }\end{array}$ & $\begin{array}{r}T_{c} \\
s \\
\end{array}$ & $\begin{array}{l}c \\
-1)\end{array}$ & $\begin{array}{c}R_{c} \\
\left(s^{-1}\right) \\
\end{array}$ & $\begin{array}{c}\text { Multiplicafion } \\
\text { correction } \\
R_{m c} \\
\end{array}$ & $\frac{R_{\mathrm{mc}}}{\mathrm{g}}$ & $M_{Q}{ }^{(b)}$ & $\mathrm{R}_{\mathrm{mc}}{ }^{(\mathrm{c})}$ & $\mathrm{M}^{(\mathrm{c})}$ \\
\hline 1 & 1.997 & 298 & 543 & 13045 & 8504 & 4.79 & 1.097 & 4949 & 1.246 \\
\hline 2 & 1.996 & 298 & 470 & 12925 & 8509 & 4.88 & 1.094 & 4949 & 1.243 \\
\hline 3 & 1.975 & 292 & 889 & 13089 & 8538 & 4.91 & 1.098 & 4952 & 1.250 \\
\hline 4 & 1.910 & 275 & 708 & 12594 & 7798 & 4.95 & 1.110 & 4527 & 1.263 \\
\hline 5 & 1.840 & 256 & 907 & 10745 & 6792 & 4.88 & 1.100 & 3964 & 1.246 \\
\hline 6 & 1.807 & 247 & 856 & 10117 & 6768 & 4.94 & 1.088 & 3941 & 1.232 \\
\hline 7 & 1.784 & 241 & 661 & 8884 & 6655 & 5.16 & 1.061 & 3894 & 1.196 \\
\hline 8 & 1.759 & 234 & 926 & 9454 & 6274 & 4.84 & 1.089 & 3.664 & 1.231 \\
\hline 9 & 1.715 & 222 & 656 & 8710 & 6151 & 4.95 & 1.075 & 3605 & 1.215 \\
\hline 10 & 1.676 & 211 & 773 & 8134 & 5669 & 4.86 & 1.077 & 3291 & 1.217 \\
\hline 11 & 1.799 & 245 & 794 & 6851 & 5319 & 5.05 & 1.046 & 3184 & 1.156 \\
\hline 12 & 1.655 & 205 & 755 & 7117 & 5703 & 5.37 & 1.046 & 3349 & 1.176 \\
\hline 13 & 1.679 & 212 & 436 & 11043 & 5246 & 5.09 & 1.173 & 3035 & 1.338 \\
\hline 14 & 1.561 & 178 & 851 & 6982 & 4727 & 4.88 & 1.083 & 2765 & 1.223 \\
\hline 15 & 1.473 & 153 & 219 & 5082 & 4270 & 4.93 & 1.036 & 2511 & 1.162 \\
\hline 16 & 1.470 & 152 & 278 & 6491 & 4362 & 4.73 & 1.089 & 2537 & 1.237 \\
\hline $17^{(d)}$ & 1.623 & (196 & 696) & (3 678) & $(4714)$ & $(5.64)$ & $(0.96)$ & $(2860)$ & $(1.046)$ \\
\hline 18 & 1.705 & 219 & 839 & 6896 & 4376 & 5.58 & 1.083 & 2605 & 1.202 \\
\hline 19 & 1.679 & 212 & 661 & 6578 & 4584 & 5.92 & 1.067 & 2726 & 1.186 \\
\hline
\end{tabular}

\begin{tabular}{|c|c|c|c|}
\hline Average & & & 5.04 \\
\hline Scatter $(1 \sigma)$ & & & \pm 0.30 \\
\hline$l \sigma(\xi)$ & & & \pm 5.6 \\
\hline$C f \quad(D-372)$ & 940 & 76.0 & \\
\hline $\mathrm{Cf}-2$ & 8100 & 624 & \\
\hline
\end{tabular}

(a) The colncidence deadtime coefficient was $\delta=2.8 \mu \mathrm{s}$.

(b) $M_{2}=$ leakage multiplication; multiplication calculated by MACT with $\rho_{0}=0.0427$.

(c) multiplication calculated using IAEA CAL4 program with $\rho_{0}=0.0282$.

(d) Paulty measurement with the NMACT counter onitted from average. 
TABLE VIII

NEUTRON DATA SUMMARY FOR BNFL COUNTER

\begin{tabular}{|c|c|c|c|c|c|c|c|}
\hline Sample & $\begin{array}{l}\text { Deadt ime }(a) \\
\text { Correction }\end{array}$ & $\begin{array}{c}T_{c} \\
\left(s^{-1}\right) \\
\end{array}$ & $\begin{array}{c}R_{c} \\
\left(s^{-1}\right)\end{array}$ & $\begin{array}{l}\text { Multiple (b) } \\
\text { Correction } \\
R_{\mathrm{mc}} \\
\end{array}$ & $\frac{R_{\mathrm{mc}}}{\mathrm{g}}$ & $R_{m c}{ }^{(b)}$ & $\mathbf{M}_{\ell}^{(b)}$ \\
\hline 1 & 1.560 & 363926 & $43 \quad 132$ & 12054 & 6.79 & 13638 & 1.304 \\
\hline 2 & 1.648 & 359078 & 42185 & 11963 & 6.86 & 13460 & 1.301 \\
\hline 3 & 1.632 & 351702 & 41899 & 12006 & 6.90 & 13516 & 1.301 \\
\hline 4 & 1.580 & 328476 & 36740 & 11195 & 7.11 & 12611 & 1.278 \\
\hline 5 & 1.532 & 306597 & 32300 & 9708 & 6.97 & 10968 & 1.271 \\
\hline 6 & 1.513 & 297455 & 30263 & 9846 & 7.19 & 11003 & 1.252 \\
\hline 7 & 1.494 & $288 \quad 294$ & 27638 & 9573 & 7.42 & 10660 & 1.233 \\
\hline 8 & 1.477 & $280 \quad 259$ & 27858 & 9106 & 7.03 & 10200 & 1.248 \\
\hline 9 & 1.449 & 266270 & 25777 & 9034 & 7.27 & 10053 & 2.232 \\
\hline 10 & 1.415 & 249274 & 22653 & 8319 & 7.13 & 9241 & 1.215 \\
\hline 11 & 1.490 & $286 \quad 638$ & 23006 & 7519 & 7.14 & 8324 & 1.220 \\
\hline 12 & 1.403 & $243 \quad 163$ & 20403 & 8461 & 7.97 & 9291 & 1.185 \\
\hline 13 & 1.353 & 217238 & 18734 & 7453 & 7.24 & $8 \quad 217$ & 1.195 \\
\hline 14 & 1.332 & 205898 & 17754 & 6969 & 7.19 & 7689 & 1.197 \\
\hline 15 & 1.278 & $176 \quad 420$ & 14145 & 5369 & 7.36 & 6796 & 1.170 \\
\hline 15 & 1.276 & 175036 & 16154 & 65.32 & 7.09 & 7096 & 1.202 \\
\hline 17 & 1.372 & $227 \quad 469$ & 14606 & 5316 & 6.36 & 7142 & 1.145 \\
\hline 18 & 1.354 & 217450 & 13653 & 5353 & 6.83 & 6367 & 1.151 \\
\hline 19 & 1.343 & 211968 & 13127 & 5559 & 7.17 & 6718 & 1.135 \\
\hline
\end{tabular}

Average

7.10

$\pm 0.32$

Scatter $(10)$

$\pm 4.5$

$10(8)$

128.9

(a) The coincidence deadtime coefficient was $\delta=\left(1.38+0.58 \mathrm{~T} \cdot 10^{-6}\right)$ $\mu \mathrm{s}$.

(b) The multiplication-corrected rates and leakage multiplication $\left(H_{\ell}\right)$ are based on the IAEA CaL4 program (new method) and $\rho_{0}=0.0667$. 
where the coincidence coefficient $\delta$ and the totals deadtime coefficient $\delta_{T}$ are given in Table III. A slightly different equation was used for the BNFL counter totals correction.

The counter IAEA-1 was positioned close to the concrete wall, and an empirical correction (see Sec. V.H) was applied to the data listed in Table IV. The measured results were divided by 1.015 for the totals rates and 1.03 for the reals.

The data Erom sample 17 in the PPNCC counter were Eaulty by a factor of $\sim 2$ in the coincidence rate and a factor of 1.14 in the totals rate. The original data were examined and all six runs of $100 \mathrm{~s}$ each were consistently low, so the faulty data were not caused by a transmission/recording error or a momentary electronic failure. The sample may have been mispositioned, or the lid may have been left off the counter, or gamma-ray pileup problems occurred. This result was omitted from subsequent averages and comparisons.

Detalls concerning the multiplication results are given in Sec. VII. The reals rate after multiplicaticn corrections $\left(\mathrm{R}_{\mathrm{mc}}\right)$ should be a linear function of the spontaneous-fission rate or of $\mathrm{g}{ }^{240} \mathrm{pu}$-effective. Thus, the $\mathrm{R}_{\mathrm{mc}} / \mathrm{g}$ ratio should be a constant. If there is moisture in the sample or an $(\alpha, n)$ contaminant such as fluorine, then this ratio, as well as the $R_{c} / g$ ratio, will be high. Four of the systems indicated that samples 12,17 , and 19 gave high results.

\section{Totals Rate Ratios}

One parameter of interest in the consistency checks is the ratio of totals counting rates in the different systems for the same $\mathrm{PuO}_{2}$ sample and the much weaker ${ }^{252} \mathrm{CE}$ source. These consistency checks are primarily on the totals deadtime correction, sample positioning, and electronic stability. However, the $\mathrm{PuO}_{2}$ cans have different fill heights, so if the detector efficiency varies as a function of sample fill height, this variance can also affect the ratios.

Table IX gives the ratios of counter IAEA-2 to all of the other counters. The IAEA-2 counter was chosen as the reference counter because it has the smallest deadtime coefficient, and it was carefully measured before the exercise.

The large totals rates ( 150000 to $550000 \mathrm{~s}^{-1}$ ) and long counting times $(\sim 600 \mathrm{~s})$ resulted in very sinall statistical errors in the totals rates. The 
TABLB IX

CONSISTENCY RATIOS POR DEADTIRB-CORRBCTED TOTALS AND REALS RATES POR THB PIVB NEUTTRON SYSTERTS

\begin{tabular}{|c|c|c|c|c|c|c|c|c|c|c|}
\hline \multirow[b]{2}{*}{$\begin{array}{l}\text { Sanple } \\
\text { No. }\end{array}$} & \multicolumn{5}{|c|}{$\frac{\text { IAEa-2 } T_{c}}{T_{c}}$} & \multicolumn{5}{|c|}{$\frac{\operatorname{IABA}-2 R_{c}}{R_{C}}$} \\
\hline & $\begin{array}{c}\text { IAm-2 } \\
T_{c} \\
\left(s^{-1}\right) \\
\end{array}$ & $\underline{I A E}-1$ & $\begin{array}{l}\text { EURATLN } \\
\text { Los Alanos }\end{array}$ & PPICC & Bur & $\begin{array}{c}\text { IAER-2 } \\
R_{c} \\
\left(s^{-1}\right)\end{array}$ & InEM-1 & $\begin{array}{l}\text { BURATON/ } \\
\text { Los Rlanios }\end{array}$ & PPHCC & BNPL \\
\hline 1 & 549062 & 0.9785 & 1.020 & 1.8 .39 & 1.509 & 97864 & 0.9579 & 1.044 & 7.502 & 2.269 \\
\hline 2 & 539365 & 0.9775 & 1.016 & 1.807 & 1.502 & 94787 & 0.9537 & 1.028 & 7.334 & 2.247 \\
\hline 3 & 529737 & 0.9784 & 1.020 & 1.809 & 1.506 & 94564 & 0.9535 & 1.042 & 7.225 & 2.257 \\
\hline 4 & 495389 & 0.9807 & 1.021 & 1.800 & 1.511 & 86096 & 0.9548 & 1.042 & 6.836 & 2.343 \\
\hline 5 & 459164 & 0.9783 & 1.017 & 1.787 & 1.498 & 73627 & 0.9586 & 1.022 & 6.852 & 2.279 \\
\hline 6 & 441746 & 0.9834 & 1.025 & $1.78 \mathrm{i}$ & 1.485 & 67306 & 0.9558 & 1.043 & 6.653 & 2.224 \\
\hline 7 & 430581 & 0.9794 & 1.015 & 1.782 & 1.494 & 62403 & 0.9508 & 1.020 & 7.024 & 2.258 \\
\hline 8 & 419202 & 0.9815 & 1.028 & 1.784 & 1.496 & 63049 & 0.9653 & 1.052 & 6.669 & 2.263 \\
\hline 5 & 395200 & 0.9803 & 1.026 & 1.775 & 1.484 & 57575 & 0.9630 & 1.051 & 6.610 & 2.234 \\
\hline 10 & 374950 & 0.9780 & 1.019 & 1.771 & 1.504 & 53280 & 0.9641 & 1.035 & 6.550 & 2.352 \\
\hline 11 & 434871 & 0.9808 & 1.023 & 1.769 & 1.517 & 54786 & 0.9362 & 1.039 & 7.997 & 2.381 \\
\hline 12 & 363353 & 0.9799 & 1.026 & 1.766 & 1.494 & 46958 & 0.9585 & 1.047 & 6.598 & 2.302 \\
\hline 13 & $324 \quad 105$ & 0.9781 & 1.026 & 1.526 & 1.492 & 12630 & 0.9503 & 1.045 & 3.860 & 2.276 \\
\hline 14 & 315708 & 0.3815 & 1.021 & 1.765 & 1.533 & 43033 & 0.9656 & 1.034 & 6.163 & 2.423 \\
\hline 15 & 267028 & 0.9809 & 1.019 & 1.743 & 1.514 & 33400 & 0.9685 & 1.039 & 6.572 & 2.361 \\
\hline 16 & 268749 & 0.9828 & 1.020 & 1.765 & 1.535 & 36818 & 0.9588 & 1.031 & 5.980 & 2.463 \\
\hline 17 & 341519 & 0.9793 & 1.026 & $(1.736)^{\mathrm{a}}$ & 1,501 & $3353 i j$ & 0.9638 & 1.040 & $(9.116)^{\mathrm{A}}$ & 2.926 \\
\hline 18 & 332811 & 0.9816 & 1.019 & 1.314 & 1.531 & 33565 & 0.9633 & 1.032 & 1.867 & 2.458 \\
\hline 19 & 324701 & 0.9811 & 1.022 & 1.527 & 1.532 & 32032 & 0.9582 & 1.026 & 4.870 & 2.440 \\
\hline Average & & 0.9803 & 1.021 & 1.739 & 2.507 & & 0.9591 & 2.037 & 6.453 & 2.319 \\
\hline scatter & $(1 \sigma)$ & \pm 0.002 & \pm 0.004 & \pm 0.099 & \pm 0.016 & & \pm 0.005 & \pm 0.009 & \pm 1.02 & \pm 0.074 \\
\hline $1 \sigma(\xi)$ & & \pm 0.2 & \pm 0.4 & \pm 5.7 & \pm 1.1 & & \pm 0.5 & \pm 0.9 & \pm 1.5 .8 & \pm 3.2 \\
\hline CE $(D-37$ & 72) 1600 & 0.985 & 1.012 & 1.703 & - & 308.0 & 0.969 & 1.035 & 4.053 & 2.389 \\
\hline
\end{tabular}

apaulty beasurement whth PPNCe counter omitted from average and $\sigma$. 
statistical errors ranged from 0.01 to $0.005 \%$, and they were completely negligible when compared with other sources of error, such as

- electronic stability,

- sample positioning, and

- variable reflection from bodies in the measurement room.

The observed scatter in the totals ratios was only 0.28 and 0.48 for IAEA-1 and EURATOM/LOS Alamos systems, respectively, and 5.78 and 1.18 for the NMACT and BNFL systems, respectively.

\section{Reals Rate Ratios}

The scatter in the reals ratio is expected to be a factor of 2 larger than the totals error for efficiency instabilities such as the above three items. Deadtime errors also are larger for the reals than the totals by a factor of $\sim 4$. In addition, the deadtime errors will show a systematic trend in going from the low-totals-rate samples (for example, sample 16 and the ${ }^{252} \mathrm{cf}$ source) to the inigh-rate samples (for example, sample 1).

The observed scatter in the reals ratio is 0.58 and 0.98 for the IAEA-1 and EURATOM/Los Alamos systems, respectively, and $15.8 \%$ and $3.2 \%$ for the NMACT and BNFL systeins, respectively. This scatter in the reals is a factor of 2 larger than the totals for the IAEA-l and EURATOM/Los Alamios systems and a factor of 3 larger for the NMACT, and the BNFL systems, as expected.

The statistical counting errors in the reals rates are given in tible $x$. These standard deviations were calculated from the expression

$$
\sigma \%=\sqrt{(R+A)+A} \cdot \frac{1008}{R}
$$

where $A$ is the accidental count rate. This expression gives a o that is too large wher $A>T$, as is the case with the present data. These standard deviations will be used later to help quantify the sources of errors on the basis that the total error is the combination of the statistical error and the other sources of error. 
TABLE X

STATISTICAL COUNTING ERRORS FOR THE RANGE OF SAMPLES

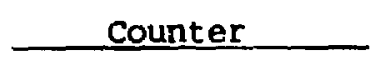

IAEA-1, 2

EURATOM/LOS Alamos

NIACT

BNFL

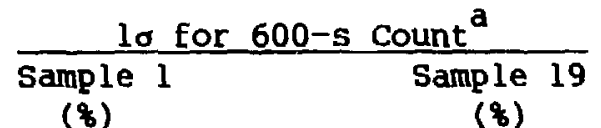

(8)

$(8)$

0.22

0.43

0.23

0.44

0.60

0.91

0.43

0.58

aThe standard deviations were calculated fron the equation $\sigma=\sqrt{(R+A)+A} \cdot \frac{100 \%}{R}$.

The sample with lowest deadtime correction is ${ }^{252}$ cf (D-372); the correction is negligible. IE there are no deadtime or geometry probleris, the totals and reals ratios (Table IX) for ${ }^{252} \mathrm{Cf}$ should be the same as for the high-rate samples. That is the case for all of the systems except the PPNCC counter, where the ${ }^{252} \mathrm{CE}$ ratio is 4.053 and the average sample ratio is 6.453 . Also, both the totals and reals ratios for the PPNCC counter are systematically lower for the lower-mass than for the higher-mass samples. These ratios indicate the deadtime correction in the PDNCC counter overcorrects at the lower rates and undercorrects at the higher rates.

These ratio differences cannot be accounted for by the difference in the functional form of $\delta(T)$. That is,

$$
\sigma(T)=a+b T
$$

vs

$$
\delta=2.8 \text { (for the NHACT system), }
$$


where $a$ and $b$ are the deadtime coefficients. To illustrate these differences, Table XI covers the counting rate of interest, and the last column gives the comparison in the two methods of calculating deadtime.

The observed reals ratio problem of 4.0 (low rate) vs 7.5 (high race) must be caused by a more serious problem, such as an electronic bias in the coincidence rate. For a normal range of samples, the calibration curve contains the same bias, and it cancels out in se - inal assay result. Thus, it could easily go unnoticed at lower couritig rates.

\section{E. Oetilers}

The ratios of $T$ and $R$ given in Table $I X$ are consistent for all of the samples (including the outliers) with only minor exceptions for the PPNCC system. Thus, the outliers are caused by sample problems rather than by instrument problems. Table XII gives some examples of instrument and sample problems that could lead to outliers.

This experiment was designed to identify and eliminate possible instrumentation problems. This goal was accomplished because we showed that instrumerit problems will change the $T$ and $R$ ratios for the different equipment. On the

TABLE XI

CONSTANT DEADTfime VS RATE-DE'PENDENT' DEADTIME

Totals

Counting

Rate $\left(s^{-1}\right)$

$\delta(T)^{a}$

$\underline{e^{\delta(T) \cdot 10^{-6}} \mathrm{~T}}$

$\underline{\mathrm{e}^{2.8 \cdot 10^{-6}} \mathrm{~T}}$

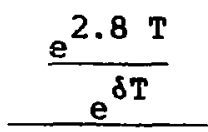

1000

2.302

1.002

1.003

1.001

50000

2.381

1.126

1.150

1.022

100000

2.462

1.279

1.323

1.035

200000

2.624

1.690

1.751

1.036

300000

2.786

2.307

2.316

1.004

400000

2.948

3.252

3.065

0.943

\footnotetext{
a Deadtime coefficient from HLNC-I $\left(2.3+1.62 \cdot 10^{-6} \mathrm{~T}\right)$ that should be similar to PPNCC counter.
} 
TABLE XII

POTENTIAL OUTLIER CAUSBS POR NEUTRON COUNTERS

\begin{tabular}{|c|c|c|c|c|}
\hline Number & Instrument problems & $\begin{array}{c}\text { Error } \\
\text { Direction }\end{array}$ & Sample Problems & $\begin{array}{c}\text { Brror } \\
\text { Direction }\end{array}$ \\
\hline 1 & Electronic noise pickup & High & $\mathrm{H}_{2} \mathrm{O}$ in $\mathrm{PuO}_{2}$ & High \\
\hline 2 & Gain change & Either & $\begin{array}{l}\text { Contaminants (Eluorine) } \\
\text { in } \mathrm{PuO}_{2}\end{array}$ & High \\
\hline 3 & Varlable efficlency profile & Either & Container change & Bither \\
\hline 4 & Loss of tubes/amplifier & Low & Matrix change & iligh \\
\hline 5 & High-voltage breakdown & High & & \\
\hline 6 & Geometry/reflect ion change & Bither & & \\
\hline 7 & Incorrect deadt Ime & E1ther & & \\
\hline 8 & Gamma-ray sensitivity & Low & & \\
\hline
\end{tabular}

other hand, the sample-related problems listed in Table XII will be common to all of the neutron systems.

Before we get to the specific calibration curves, we should mention that we can spot outliers by a high $\mathrm{R}_{\mathrm{mc}} / \mathrm{g}$ ratio. This ratio is proportional to the specific spontaneous-fission yield, and it should be a constant for each detector.

In Tables IV-VIII, we list the $\mathrm{R}_{\mathrm{mc}} / \mathrm{g}$ values with their averages and scatter about the mean. Three high outliers were 1dentified (samples 12, 17 , and 19) as being more than $2 \sigma$ above the mean. There were no low outliers. Two of these outliers (17 and 19) have high burnups and high ${ }^{241}$ An contents, indicating a longer time since chemical separation. This long separation time would give more opportunity for moisture absorption.

Samples 17-19 had a very high gamma-ray dose on contact, which may be related to their assay varlability.

\section{E. Gamma-Ray Sensitivity}

If the gamma-ray dose from the sample gets above $\sim \mathrm{l} R / \mathrm{h}$, the pileup of gamma-ray pulses can get above the neutron discrimination threshold. When this happens, the $T$ value increases rapidly and the $R$ value decreases slowly. 
Figure 3 shows the totals rate vs high voltage for the ${ }^{3}$ He tubes in a neutron system similar to the AMPTEK system being evaluated. The operating high voltage should be set below the point where the gamma pileup is significant.

The gamma-ray dose was measured for two sellafleld sample cans, using one high-dose can and one low-dose can. The measurements were made at positions $A, B$, and $C$, shown in Fig. 4, where $A$ is in contact with the can and $B$ and $C$ were measured with the can inside the HLNC-II.

Table XIII, which lists the measured doses as a function of position, shows that dose is getting close to the $1 \mathrm{R} / \mathrm{h}$ limit at the location of the ${ }^{3} \mathrm{He}$ tubes. In retrospect, a high-voltage plateau curve should have been measured for the highest dose sample.

Most of the gamma dose is coming from the ${ }^{241}$ Am $(60-k e v)$ gamma ray that is effectively shielded by the cadmium liner on the interior of the neutron detector cavities. Because the high dose is $2000 \mathrm{mrem} / \mathrm{h}$ on the inside of the detector wall and $100 \mathrm{mrem} / \mathrm{h}$ on the outside of the wall, we can estimate the dose as $-500 \mathrm{mrem} / \mathrm{h}$ at the tube location.

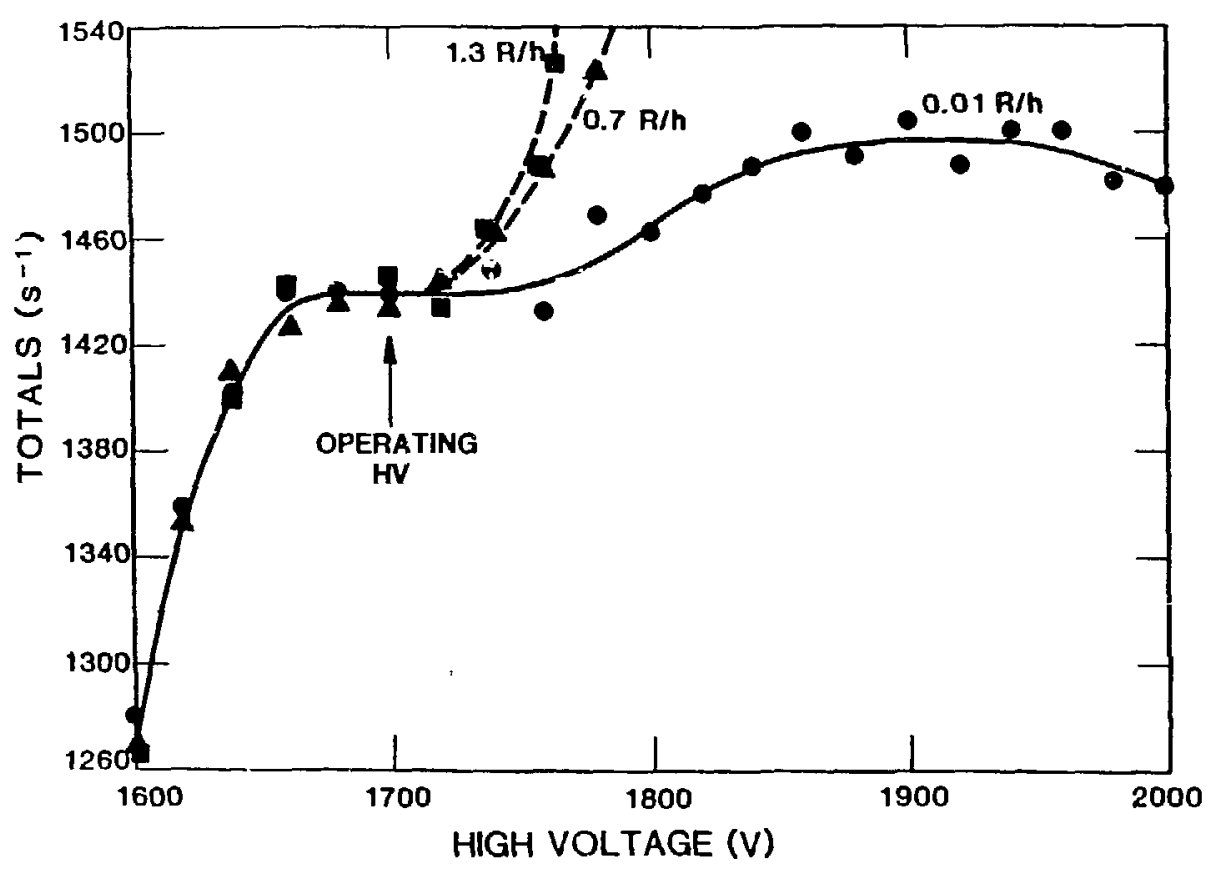

Fig. 3. Typical totals rate vs high voltage on the ${ }^{3} \mathrm{He}$ tubes for an HLNC-II system with different levels of gamma-ray exposure to the detectors. 

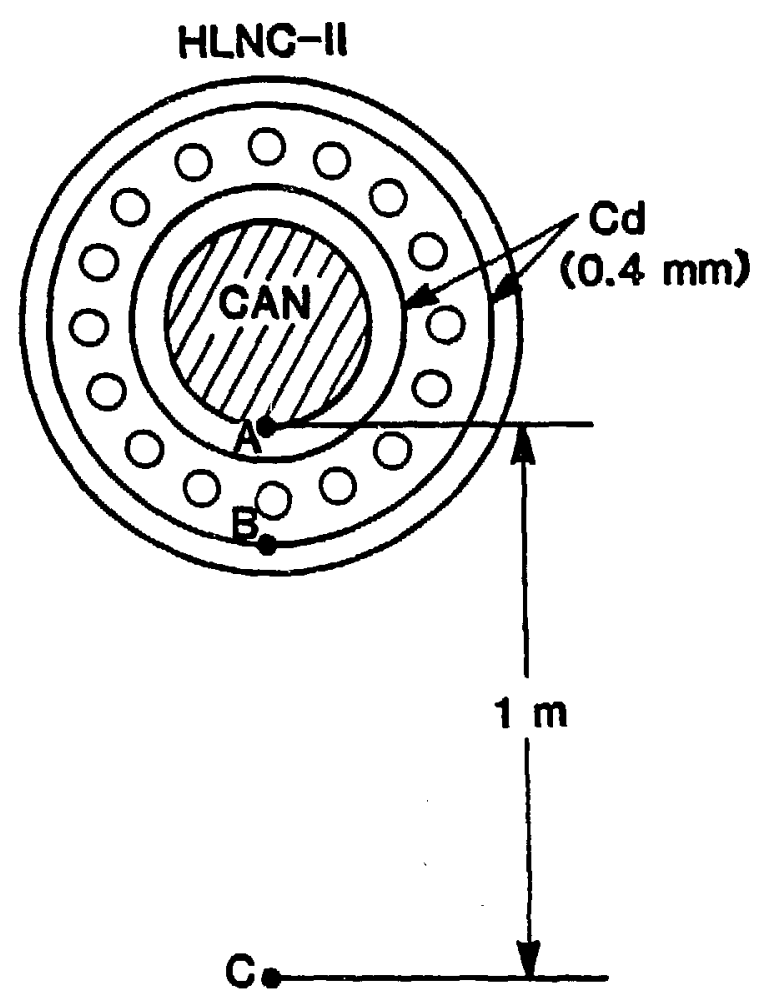

Fig. 4. Geometry for gamma-ray and neutron dose measurements where points $A, B$, and $C$ represent the measurement positions.
TABLE XIII

GAMMA-RAY DOSE MEASUREMEN'S EROM HIGH- AND LOW-DOSE CANS

Can $\underline{\text { Position }} \begin{array}{cc}\text { Gamma } & \text { Neutron } \\ \text { (mrem/h) } & \text { (mrem/h) }\end{array}$

18
A
B
C

2000

60

100

8

8

0.9

7

$\begin{array}{rrc}\text { A } & 250 & 60 \\ \text { B } & 40 & 13 \\ \text { C } & 4 & 1.2\end{array}$

The different neutron detectors should have a different sensitivity to gamma-ray pileup. The BNFL system should be the least sensitive because it has a separate preamplifier and amplifier on each ${ }^{3} \mathrm{He}$ tube, thus reducing the pileup ioad iy a factor of 3 . The totals ratio for the high- and low-dose samples is the same for the different detectors, so it would appear that there is no pileup problem.

\section{G. Sample-Positioning Errors}

To examine the variability in the result from the radial position of the sample can, using IAEA-1 we counted one of the samples in the normal center position and then repeated the count with the can touching the wall of the sample cavity. The results were as follows:

$$
\frac{T(\text { on wall })}{T(\text { center })}=\frac{343585}{342930}=1.002
$$


and

$$
\frac{R(\text { on wall) }}{R(\text { center })}=\frac{35806}{35464}=1.010
$$

and after multiplication correction,

$$
\frac{R(\text { on wal } 1)}{R(\text { center })}=\frac{15248}{15230}=1.001 .
$$

Thus, the error from radial variability in positioning the cans was negligible for the HLNC-II counters. Because the multiplication correction uses the $R / T$ ratio, the results after multiplication corrfction show even less wall perturbation than the results before multiplication correction.

\section{H. Wall-Reflection Effects}

Many of the neutrons that are emitted from the sample pass through the detector body and escape to the room. If the detector is positioned close to a high-density wall, such as concrete, neutrons will be reflected back into the detector, giving a small increase in the counting rate.

This efficiency change was measured with a ${ }^{252} \mathrm{Cf}$ source in an HLNC-II positioned at various distances from the concrete wall in the vault. The results of the measurements are shown in Fig. 5, where the distance is from the outside edge of the detector to the surface of the wall. The coincidence rate has been normalized to unity at large distances from the wall. For the work at sellafield, a wall-reflection correction (0.97) was applied only to the IAEA-l counter that was operated at $-15 \mathrm{~cm}$ from the wall. The other counters were far enough away from the wall to make the correction negligible.

\section{CALIBRATTON RESULTS}

For brevity, this section dealing with calibration results examines only one of the five systems. The results for any of the other systems can be 


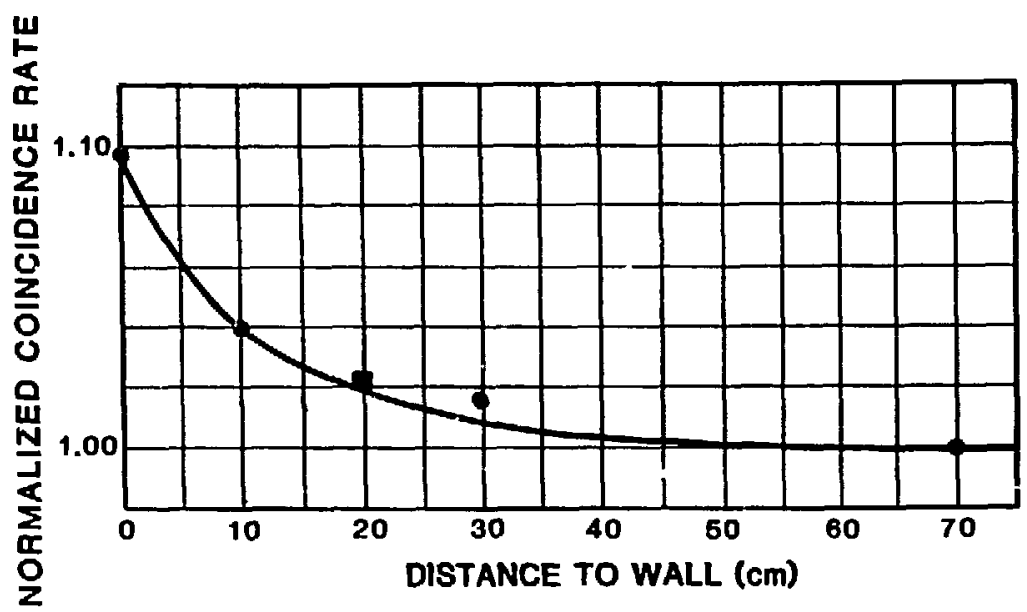

Fig. 5. Coincidence rate increase (HLNC-II) from concrete wall reflection vs distance between side of detector and wall.

obtained from the ratios given in Table IX. The EURATOM/Los Alamos system is used as the reference system, so the present results can be combined with measurements at Los Alamos ${ }^{1}$ and Belgonucleaire ${ }^{8}$ to extend the mass that the calibration covers from a few grams to $7.2 \mathrm{~kg}$ of $\mathrm{PuO}_{2}$.

We calibrated the detector for the data both before and after multiplication corrections, and we used the alpha-corrected totals rate to help Identify outliers.

\section{A. Sample-Container Correction}

The thick-walled sample containers give a small percentage of increase in the neutron rate, so we corrected for this effect before conparison with results from thin-walled cans.

To do this, the ${ }^{252}$ Cf source $(D-372)$ was measured inside a double-walled container. The results were

$$
\frac{\mathrm{R}(\mathrm{Cf} \text { inside can })}{\mathrm{R}(\mathrm{Cf} \text { no can })}=1.027,
$$

and the totals correction was 1.013 . Thus, the $T$ and $R$ rates given in Table VI should be divided by these factors for the calibration. 
B. Californium-252 Source Normalization

The source (D-372) gave a rate in counter IAEA-2 of

$R(D-372)=297.7 \pm 2.0$ (on $85-01-30)$.

This is our reference rate; we normalized the sellafield data to the data taken at Belgonucleaire and Los Alamos using the EURATOM/Los Alamos counter.

Belgonucleaire (EURATOM/Los Alamos Counter). The neutron source reference rate at Belgonucleaire was

$$
R(D-372)=329.6 \pm 1 \text { (on 84-09-24). }
$$

The time interval between the Belgium work and the measurements in the United kingdom was

$$
\begin{aligned}
\text { Time lapse } & =0.345 \mathrm{y}, \\
\mathrm{e}^{-\lambda t} & =0.913, \text { so } \\
R(\operatorname{cor} r) & =301.1 \text { (on } 85-01-30) .
\end{aligned}
$$

The source normalization constant is

$$
\frac{\mathrm{R}(\text { Sellafield })}{\mathrm{R}(\text { Belgonucleaire })}=\frac{297.7}{301.1}=0.9887 \text {. }
$$


To directly compare the prior data with the present data, we need to divide the seliafield reals rates by a factor of

$$
\underbrace{(1.027)}_{\begin{array}{c}
\text { Sample } \\
\text { Container }
\end{array}} \cdot \underbrace{(0.9887)}_{\text {Cf Norm. }}=1.015
$$

and the totals rates by 1.008 .

\section{Deadtime Correction}

The data taken at Belgonucleaire with the EURATOM/Los Alamos counter were evaluated using the erroneous deadtime coefficient of

$$
\delta=\left(0.62+0.2 \cdot 10^{-6} \mathrm{~T}\right) \mu \mathrm{S} .
$$

The value used at sellafield (based on more recent measurements) was

$$
\delta=\left(0.68+0.22 \cdot 10^{-6} \mathrm{~T}\right) \mu \mathrm{s} .
$$

Thus, a small correction was applied to the prior Belgonucleaire data.

\section{Updated Results Covering Lower Mass Range}

The data taken at Belgonucleaire using the EURATOM/Los Alamos counter have been updated with the new value of $\delta=0.68+0.22 \cdot 10^{-6} \mathrm{~T}$, and the results are listed in Table XIV. The "green" samples with high moisture content were onitted from the table.

Similar data taken at Los Alamos for masses of 10 to $150 \mathrm{~g}^{240} \mathrm{Pu}-$ effective are given in Table XV. In this case, the counting rates were so low that the change in $\delta$ made a negligible difference in the results.

The multiplication-corrected reals per gram value is slightly less for these samples because the small mass gives less neutron scattering than the 
TABLE XIV

MEASUREMENT RESULTS FOR BELGONUCLEAIRE PUO 2 IN HLNC-II COUNTER EURATOM/LOS ALAMOS

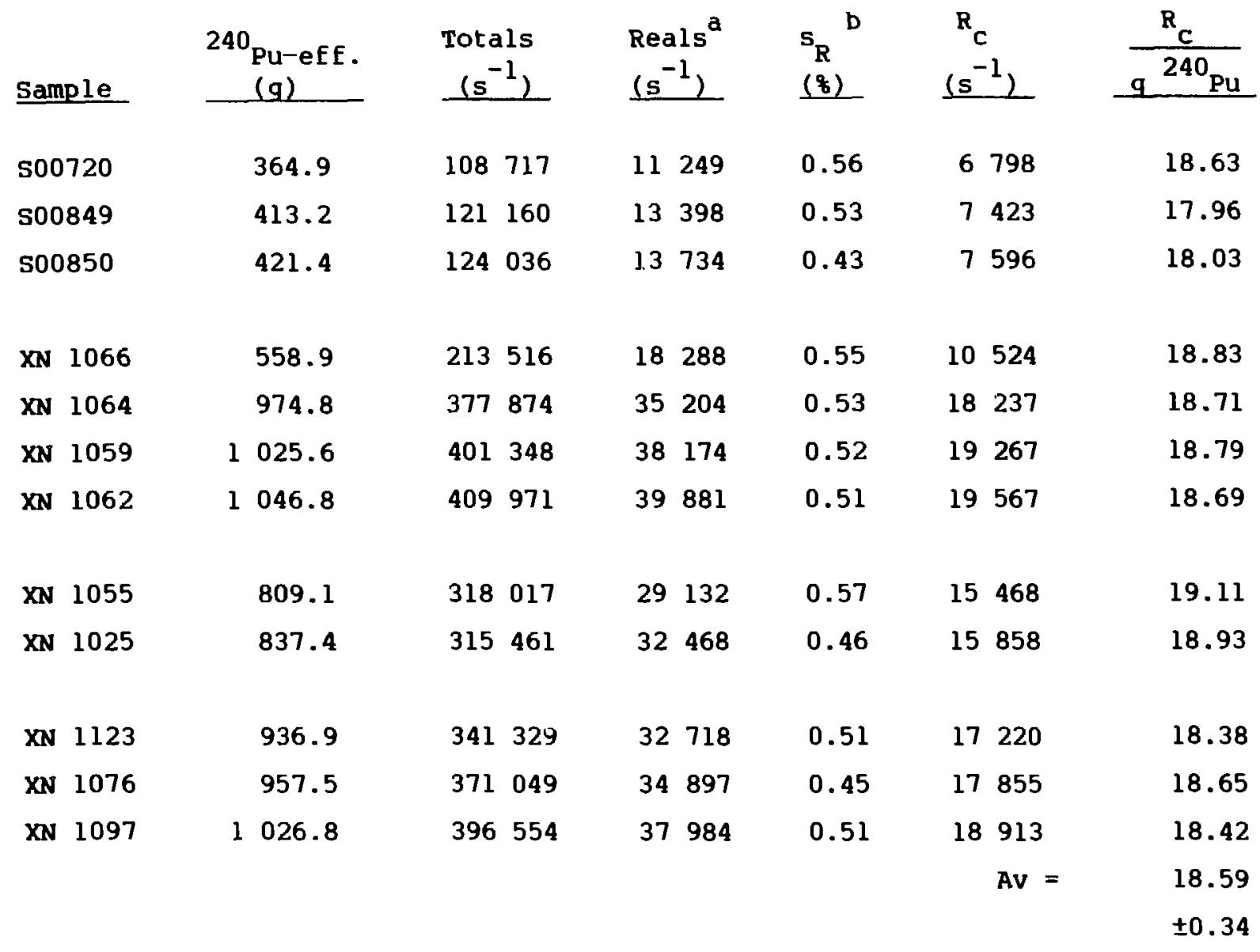

CE $(D-372)^{C}$

1744

$329.6 \quad 0.04$

aThe totals and reals rates have been corrected for steel double containers, room background ( 40 counts $/ \mathrm{s})$, and deadtime, $\delta=\left(0.68+0.22 \cdot 10^{-6} \mathrm{~T}\right) \mu \mathrm{s}$. $b_{\text {The }} s_{R}(\xi)$ is the observed standard deviation of repeat runs about the mean value of $R$.

C Measured on $9 / 24 / 84$; the ratio of $D-372 / C R-5=0.1578 \pm 0.001$. 
TABLE XV

MEASUREAENT RESULTS FOR LOS ALAHOS PUO 2 IN HLNC-II

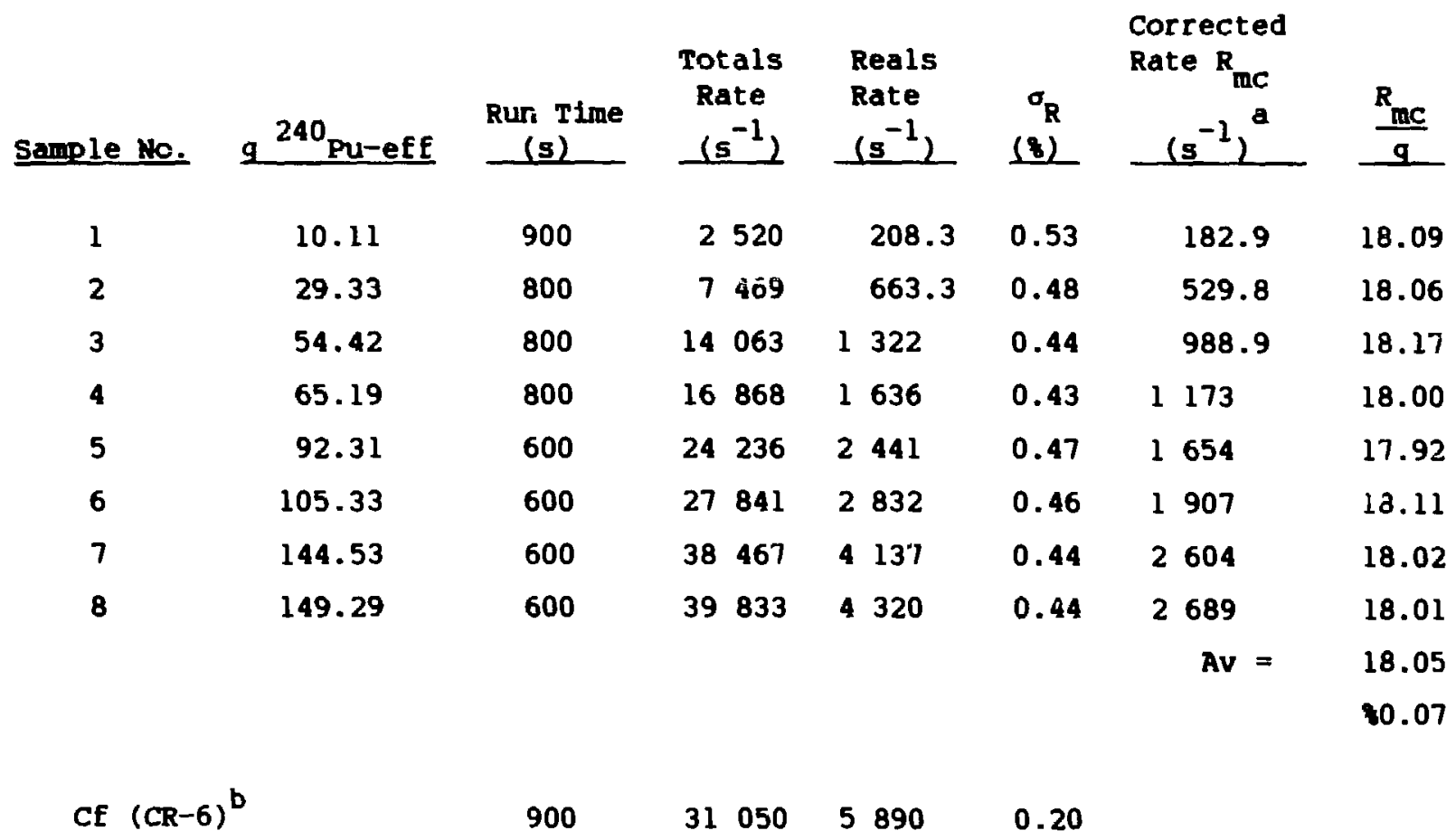

arultiplication correction made with Method 2.

byeasured on $6 / 6 / 84$.

larger samples do. The scattered neutrons have lower energy and thus a higher detection efficiency $(\varepsilon)$ in the EURATOM/LOS Alamos counter.

\section{E. EURATOM/LOS Alamos Calibration Results}

Table XVI gives the Sellafield data for the EURATOM/Los Alamos counter corrected for deadtime, ${ }^{252} \mathrm{Cf}$ normalization, and sample containers (wall thickness). This amounts to dividing the Table VI base data by a factor of 1.015 for $R$ and 1.008 for $T$ (see Sec. VI.B). The $R_{m c}$ values decrease by $a$ factor of only $\sim 1.006$.

The calibration curves for $R$ and $R_{m c}$ are shown in Fig. 6, where in addition to the sellafield data, the lower-mass data from Belgonucleaire and Los Alamos are shown for comparison. The three outliers (samples 12, 17, and 19) are shown on the graph, but they were not included in the calibration curve 
TABLE XVI

SELLAFIELD CALIBRATION SUMARRY FOR COUNTER EURATOM/LOS ALAMOS

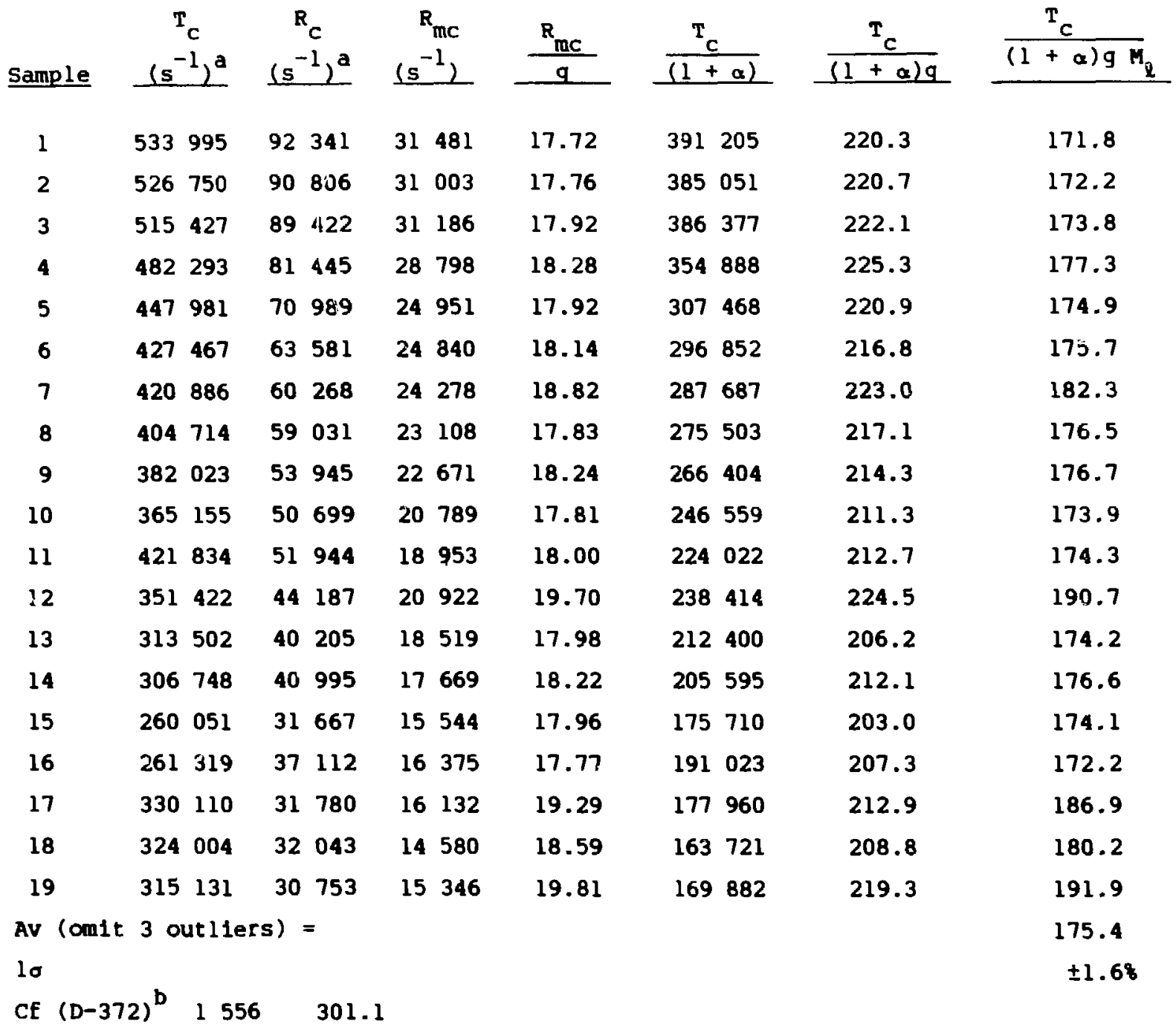

\footnotetext{
aThe coincldence deadtime coefflcient was $\delta=\left(0.68+0.22 \cdot 10^{-6} \mathrm{~T}\right) \mu \mathrm{s}$, the sample-container correction was 0.974 , and the efficiency correction was 1.011 . bvalues reflect efficiency correction on 85-01-30.
} 


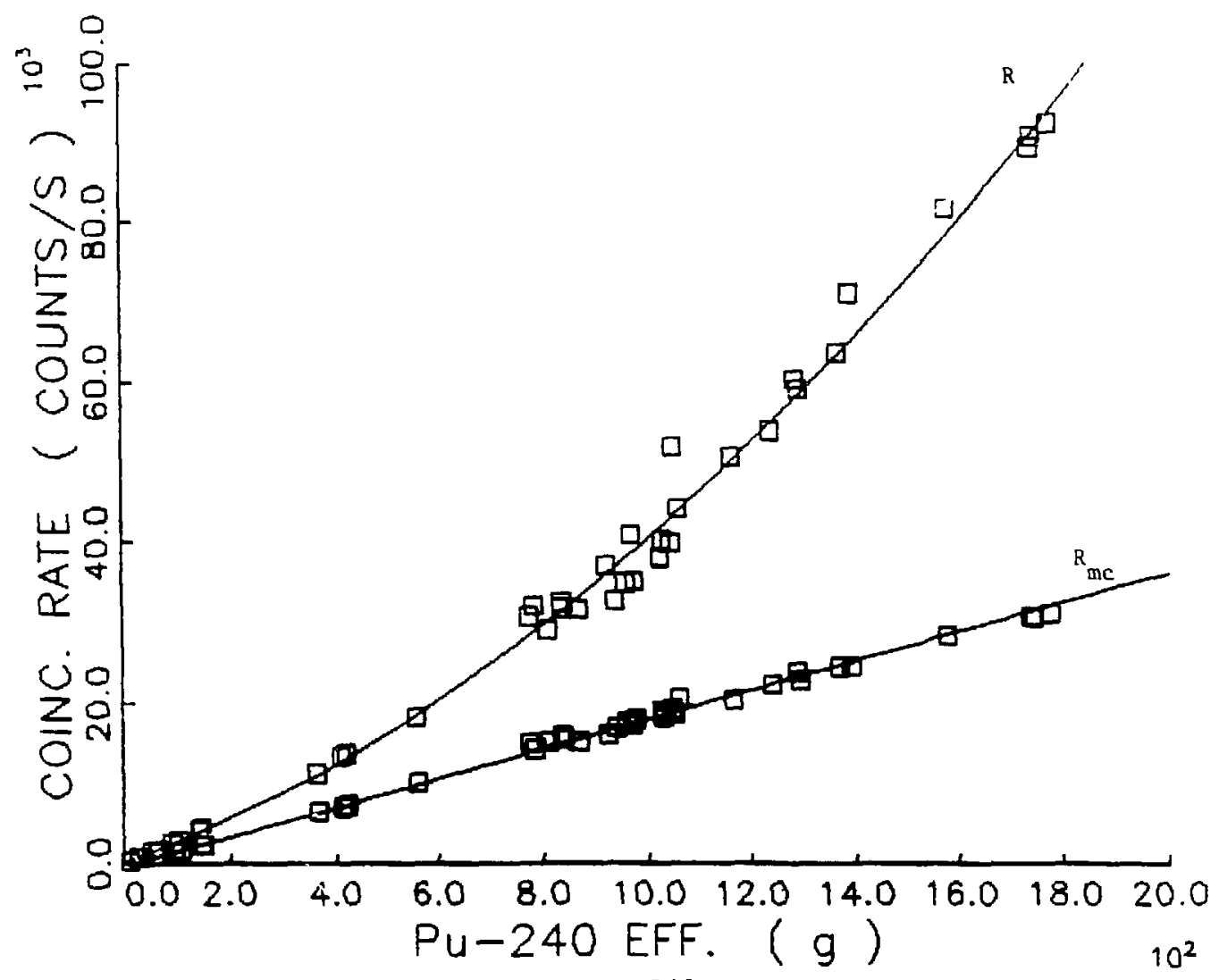

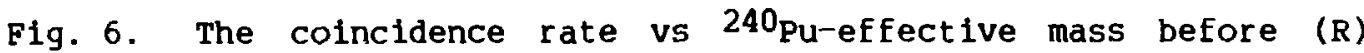
and after ( $R_{\mathrm{mc}}$ ) multiplication corrections for the extended data set.

fit. Several of the high points on the $R$ curve are not the identified "outliers," but they are legitimately high because of very high a values. The exira $(\alpha, n)$ neutrons induce additional fissions (multiplication) in the plutonium. The standard multiplication correction adequately corrects for this effect, and thus those samples are not necessarily outliers on the curve for $R_{\text {mc }}$ vs mass.

The calibration parameters are listed in Table XVII for the EURATOM/Los Alamos counter. The sellafield data set (high mass) and the extended data set (36 samples) were both fit with a quadratic function of the form

$$
\mathrm{R}=\mathrm{aM} \mathrm{M}^{2}+\mathrm{bM}+\mathrm{c},
$$


TABLE XVII

CALIBRATION PARAMETERS FOR EURATOM/LOS ALAMOS COUNTER(a)

\section{Sample Group}

(1) 36 samples (no mc)

(1) 36 samples (me)

(2) 16 Sellafield (no mc)

(2) 16 Sellafield (mc)

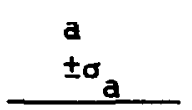

0.014963

$\pm 0.000803$

0

0

0.008287

$\pm 0.00827$

0

0

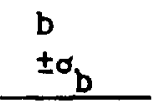

25.283

$\pm 0.7033$

18.168

$\pm 0.0658$

42.527

$\pm 21.73$

18.020

$\pm 0.0748$

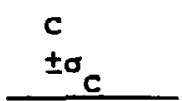

$|\bar{\Delta}|$

(8)

(b) 
- americium-241 contents from 670 to $33814 \mathrm{ppm}$,

- four different container types and geometries, and

- three different facilities and dates for the data collection.

A ${ }^{252}$ Cf source was used to normalize the detector for electronic changes, but these corrections were always $<1.28$.

When the more limited sellafield data set (16 samples) was fit, the average absolute mass residual from $R_{m c}$ was reduced to $1.28 \%$. The three outliers were 68 to $8 \%$ above the calibrition curve. Figure 7 shows the $R_{m c}$ values for the sellafield data set with an expanded scale to show the three outliers.

The following section examines the totals rates to see if they are anomalous for the outliers.

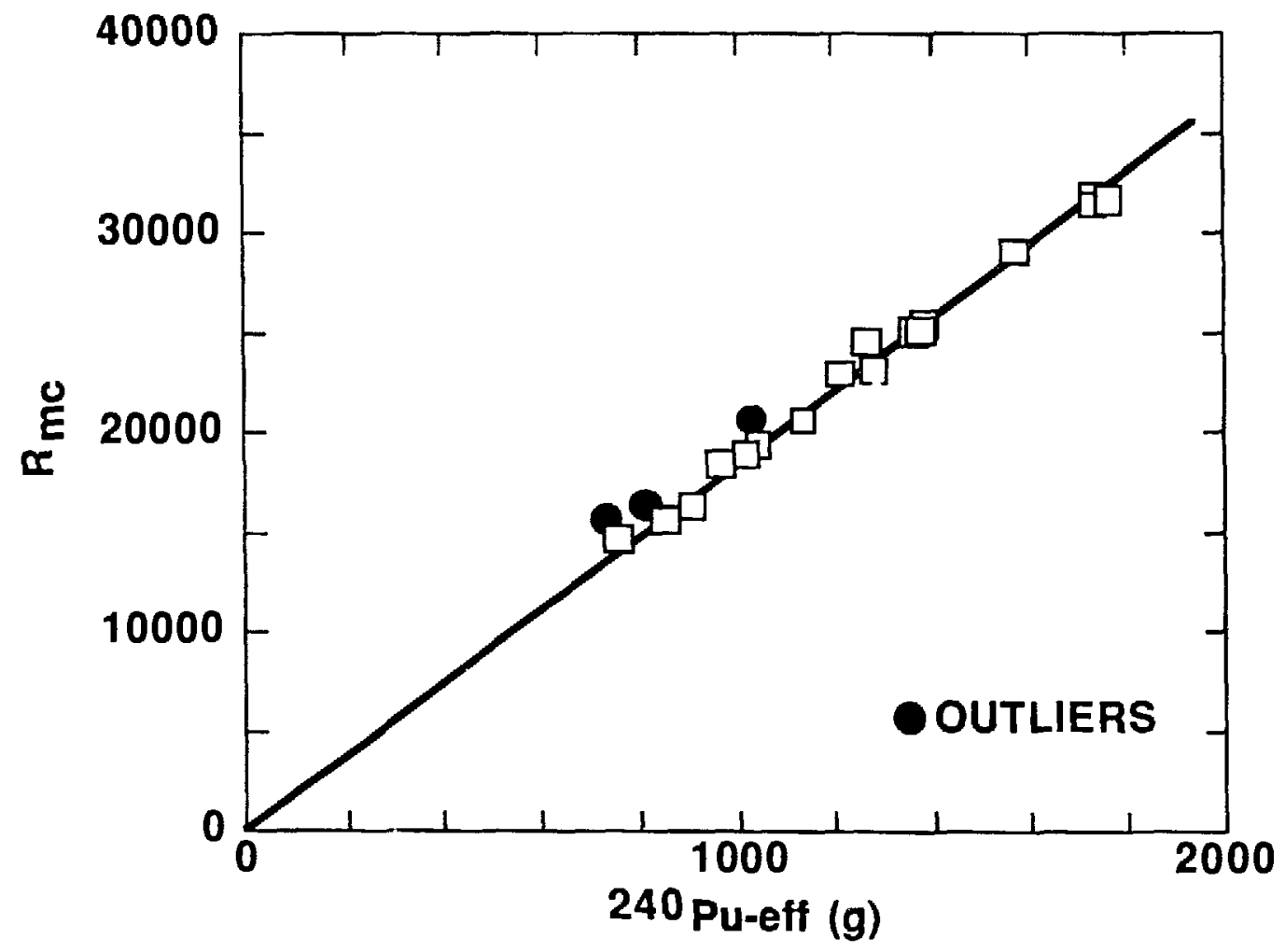

Fig. 7. The multiplication-corrected reals rate vs ${ }^{240}$ Pu-effective for the sellafield samples, with an expanded scale to show the outliers. 


\section{F. Totals Rate Analysis}

The totals rate can indicate a variable $(\alpha, n)$ problem in a sample because the observed $T$ will increase when $(\alpha, n)$ emitters (for example, fluorine or $\mathrm{H}_{2} \mathrm{O}$ ) are present. The observed totals rate can be written as .

$$
T=T(\text { spontaneous fission })+T(\alpha, n)+T(\text { induced fission }),
$$

or

$$
T=T(S F)+T(\alpha, n)+T(I F) .
$$

The spontaneous-fission rate is directly proportional to the $\mathrm{g}{ }^{240} \mathrm{Pu}-$ effective. However, we have measured $T$, so we must correct it for $(\alpha, n)$ neutrons and induced-fission neutrons as follows:

The calculated ratio $\alpha$ is defined as

$$
\alpha \equiv \frac{T(\alpha, n)}{T(S F)}
$$

and the leakage multiplication, $M_{\ell}$, is

$$
M_{\ell} \equiv \frac{T}{T(S F)+T(\alpha, n)}
$$


Equation (1) can be solved to give

$$
T(S F)=\frac{T}{(1+\alpha) M_{l}}
$$

and also

$$
\frac{T(S E)}{g^{240} \text { Pu-effective }}=\text { const }=\frac{T}{(1+\alpha) g M_{Q}} \text {. }
$$

This ratio should be a constant for all samples with correct values of $\alpha, M_{\ell}$, and $g{ }^{240}$ Pu-effective. If there are $(\alpha, n)$ contaminants in the sample, the calculated values of $\alpha$ and $M_{q}$ will be too small and the totals rate ratio from Eq. (2) will be too large.

This corrected totals rate ratio is directly related to the corrected reals ratio per unit mass by the multiplication constant $p_{0}$ (see sec. VII.A).

Table XVI gives this totals per gram ratio for the 19 sellafield samples, and we see that the value is high for all of the identified outliers. This ratio, corrected for multiplication and $(\alpha, n)$ neutrons, should be a constant in the EURATOH/Los Alamos counter for all normal samples. The same constant (175.4) should be valid for the other low-mass data sets given in Tables XIV and $\mathrm{XV}$, which correspond to the same detector.

The average value of $\mathrm{T} /(1+\alpha) \mathrm{g} \mathrm{M}_{\ell}$ for the sellafield data set was $175.4 \pm 2.8$. This value can be compared with the average value of $174.4 \pm 1.4$ for the Los Alamos samples ( 10 to $150 \mathrm{~g}^{240} \mathrm{Pu}$-effective) and $179.2 \pm 5.3$ for the Belgonucleaire samples (365 to $1027 \mathrm{~g}{ }^{240}$ Pu-effective). The stated uncertainties are the scatter of the ratios in the individual data sets. The typical sample at Belgonucleaire had a molsture content $>5000 \mathrm{ppm} \mathrm{H}_{2} \mathrm{O}$. 


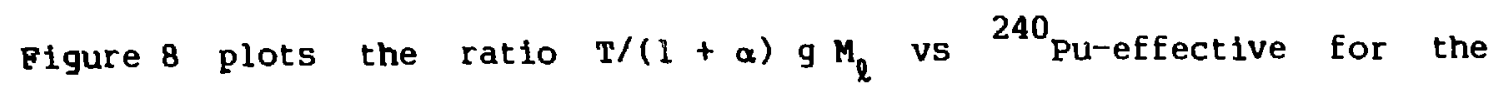
EURATOM/Los Alamos detector. The outliers (samples 12, 17, and 19) are identified by circles on the plot. The deviations from the fitted horizontal straight line were $8.7 \%, 6.6 \%$, and 9.48 for samples 12,17 , and 19 , respectively. The average deviation of the other samples was 1.68 .

The present values of $M_{Q}$ were determined from the measured $R / T$ ratios and the calculated value of $\alpha$. For the outliers, $\alpha$ is in error, so the subsequent calculation of $M_{\ell}$ is also incorrect. On the other hand, if we calculated $M_{\ell}$ using Monte Carlo computer codes and the operator's vaiues of sample mass and size, then the constant value of Eq. (2) could be used to estimate $\alpha$.

The utility of the constant ratio plotted in Fig. 8 or the equivalent Fig. 7 is to help identify outliers from their anomalous totals rates. High rates can be explained by high $(\alpha, n)$ contamination or moisture in the samples.

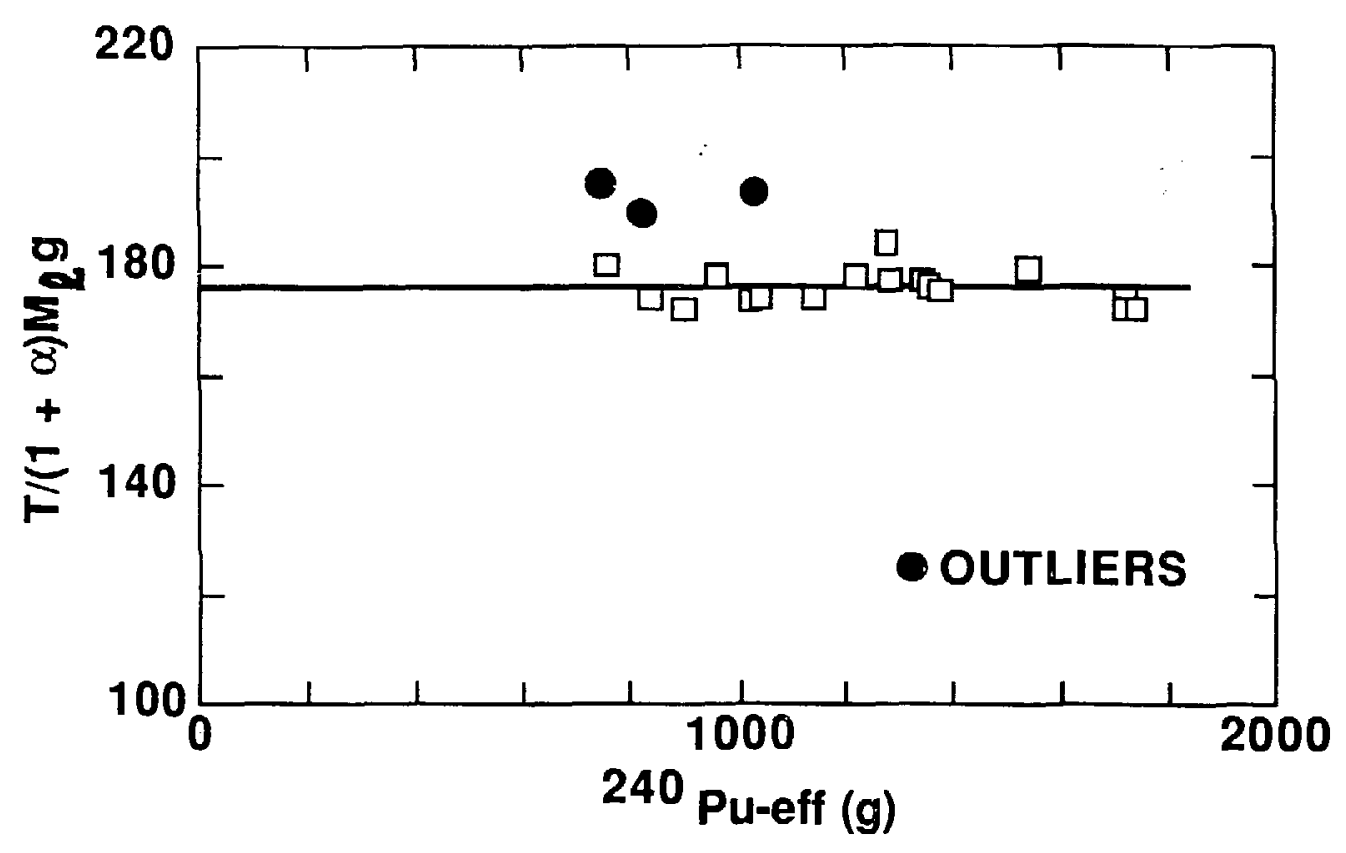

Fig. 8. The spontaneous-fission totals rate, $T /(1+\alpha) g M_{\ell}$, vs the $240 \mathrm{Pu}$-effective mass for the EURATOM/LOS Alamos detector. 
VII. MULTIPLICATION ANALYSIS

The results after multiplication correction have a scatter that is a factor of $\sim 2$ less than before the correction. This difference occurs because the correction takes care of variations in sample density, shape, and $\alpha$ (Induce fissions). These effects are more important as the sample mass increases.

A. Multiplication Equations

The multiplication corrections were made using the new equations given by Böhnel ${ }^{7}$ and Ensslin. ${ }^{8}$ They are

$$
\begin{aligned}
& \mathrm{R}_{\mathrm{mC}}=\frac{\mathrm{R}}{\mathrm{CF}}, \\
& \mathrm{CF} \equiv \mathrm{H} \cdot \mathrm{r},
\end{aligned}
$$

$$
\begin{aligned}
& r \equiv \frac{\frac{R}{T}}{\rho_{0}}(1+\alpha), \\
& \rho_{0}=\left(\frac{R}{T}\right)_{0}\left(1+\alpha_{0}\right)=0.103 \text { (For the HLNC-II), }
\end{aligned}
$$

$$
M=\frac{-B+\sqrt{B^{2}-4 A C}}{2 A} \text {, }
$$

$$
A=2.074(1+\alpha),
$$

$$
B=-(2.074 \alpha+1.074),
$$

$$
c=-\mathbf{r},
$$

$$
\alpha=\frac{134 \mathrm{E}_{238}+0.381 \mathrm{E}_{239}+1.41 \mathrm{E}_{240}+0.013 \mathrm{E}_{241}+0.02 \mathrm{E}_{242}+26.9 \mathrm{E}_{241 \mathrm{Am}}}{10.22\left(243 \mathrm{E}_{238}+\mathrm{E}_{240}+1.69 \mathrm{E}_{242}\right)},
$$

36 
where the $\mathrm{E}_{\mathrm{m}}$ values are the weight fractions of the plutonium isotopes with mass number $\mathrm{m}$.

The value of $M_{l}$ is calculated in the above equations as $M$ if the correct values of $\rho_{0}$ and $\alpha$ are used. $M_{\ell}$ is a parameter related to the mass and size of the sample, so it should have nothing to do with the particular detector (neglecting differences in neutron reflection from the detector walls). The de:ector-wall reflection of neutrons gives a small increase to $M_{\ell}$.

\section{B. Multiplication Constant}

The parameter $\rho_{0}$ is defined by

$$
\rho_{0}=\left(\frac{\mathrm{R}}{\mathrm{T}}\right)_{0}\left(1+\alpha_{0}\right)
$$

for a ronmultiplying sample. The value of $\rho_{0}$ was measured to be $\sim 0.103$ for the HLNC-II. This parameter is proportional to the singles efficiency and the fraction of time-correlated neutrons that fall within the coincidence gate.

The value of $p_{0}$ for one detector can be related to a different detector by the $R / T$ ratios in both detectors for the same sample. That is,

$$
\rho_{0}(B N F L)=\rho_{0}\left(\text { HLNC-II) } \frac{\frac{R}{T} \text { (BNFL) }}{\frac{R}{T}(H L N C-I I)} .\right.
$$

Different values of $\rho_{0}$ can be used for any detector, but it is essential that the same value of $\rho_{0}$ be used in both the calibration fit and in the actual assay. If incorrect values of $\rho_{0}$ are used, they cancel out in the calibration curve; however, $M_{2}$ will be incorrect.

For this analysis, we wanted to be able to directly compare the $M_{\ell}$ values determined from the $R / T$ measurements for each detector, so we used Eq. (3) to calculate consistent $\rho_{0}$ values for the PPNCC and BNFL detectors. 
There was so little change in the $\rho_{0}$ values for the three HLNC-II detectors that the original value $\left(\rho_{0}=0.103\right)$ was maintained for each of these systems.

A summary of the multiplication parameters is given in Table XVIII. The listings of the $R_{m c} / g$ ratios are given in Tables IV-VIII. If there are no unknown $(\alpha, n)$ or moisture problems, this ratio should be a constant for each detector. Also, Table XVIII shows the scatter of this ratio about the mean for the five systems. The three outliers (samples 12, 17, and 19) were identified.

\section{Multiplication Consistency Checks}

To invesigate the consistency in $R_{m c}$ and $M_{\ell}$ ' we processed the base data from each of the five systems using the IAEA CAL4 computer code to give consistent $R_{m c}$ and $M_{l}$ values. For each detector, the ratio of $R_{m c}$ and $\left(M_{\ell}-1\right)$ was compared with the reference system (IAEA-2).

The $\left(M_{\ell}-1\right)$ values were compared because they give a more sensitive indication of the multiplication than $M_{\ell}$ would. For example, $M_{\ell}=1.250$ means that there is a $25 \%$ increase in the net neutron leakage caused by multiplication.

TABLE XVIII

MULTIPLICATION PARAMETERS SUMMARY

\begin{tabular}{|c|c|c|c|c|c|}
\hline Detector & $\begin{array}{c}\text { or iginal } \\
P_{0} \\
\end{array}$ & $\begin{array}{c}\text { CAL4 } \\
\rho_{0} \\
\end{array}$ & $\begin{array}{l}\mathrm{R}_{\mathrm{mc}} \\
\mathrm{g} \\
\mathrm{Av}\end{array}$ & $\begin{array}{l}\frac{R_{m c}}{g} \\
\text { Omit out liers }{ }^{a} \\
\end{array}$ & $\begin{array}{l}\text { Scat ter } \\
\operatorname{lo}^{\circ}(8)^{b} \\
\end{array}$ \\
\hline IAEA- 1 & 0.103 & 0.103 & 18.91 & 18.59 & 1.2 \\
\hline IAEA-2 & 0.103 & 0.103 & 18.73 & 18.43 & 1.6 \\
\hline EURATOM/LOS Alamos & 0.103 & 0.103 & 18.41 & 18.13 & 1.6 \\
\hline NMACT & $\sim 0.0437$ & 0.0282 & 5.04 & 4.92 & 2.3 \\
\hline BNFL & $\sim 0.060$ & 0.0667 & 7.10 & 7.11 & 2.5 \\
\hline
\end{tabular}

a Average based on original po values for all systems.

bomitted outlier sample numbers 12,17 , and 19 in the average and scatter. 
If there are no problems of the type listed in Table XII, this $R_{m c}$ ratio to the reference detector will be constant for all of the samples. The variation in the ratio outside of counting statistics is an indication of deadtime or geometry problems.

Table XIX lists the ratios of $R_{m c}$ and $\left(M_{Q}-1\right)$ for all of the detectors. The scatter $(l \sigma)$ of $R_{\mathrm{mc}}$ about the mean is only \pm 0.268 for IAEA-l and $\pm 0.36 \%$ for EURATOM/Los Alamos. This scatter is very good and consistent with the counting statistics on $R(1 \sigma \simeq 0.4 \%)$. It is interesting that the scatter in $R_{m c}$ is less than half that observed in the $R$ values (Table IX) of \pm 0.58 and \pm 0.98 for the same two systems.

The BNFL detector ratios are consistent with those of the HLNC-II with about twice the scatter $( \pm 0.688)$ in $R_{m c^{*}}$

The PPNCC detector shows a systematic problem in the deadtime correction that results in a scatter of \pm 3.838 .

The average $M_{l}$ ratios for all of the systems are remarkably close to unity. The differences in the average values for the three HLNC-II systems just reflect that they have slightly different $(\sim 2 q)$ efficiencies (see Table III), but they all used the same $\rho_{0}$ value $(0.103)$.

When there is a deadtime problem, the $R / T$ ratio will be in error because the deadtime correction is approximately four times larger in $R$ than in $T$. This incorrect $R / T$ ratio will give nonphysical values for $M_{\ell}$ calculated by the equations in Sec. VII.A. Thus, the $\left(M_{\ell}-1\right)$ ratios for the PPNCC detector have a large scatter of \pm 18.78 .

\section{Multiplication Investigation}

Because $M_{\ell}$ is an intrinsic property of the sample, it is interesting to examine it for all three sample sets (Los Alamos, Belgonucleaire, and Sellafield). Figure 9 plots the $M_{\ell}$ values as a function of plutonium fissile mass from 50 to $5439 \mathrm{~g}$. The measured $R / T$ ratios and calculated $\alpha$ values were used to determine the values of $M_{\ell}$ using the multiplication equations given in $5 e c$. VII.A and the EURATOM/Los Alamos counter.

Figure 10 shows the inside diameter and maximum fill heights of the three different $\mathrm{PuO}_{2}$ containers. The low-mass Los Alamos samples fill only a few centimeters in the bottom of the can, so the sample has the shape of $\bar{a}$ disk or pancake, with very low neutron multiplication. However, as the sample mass increases to the largest Los Alamos sample ( $876 \mathrm{~g}$ of plutonium), the height is 
COMPARISON OR MULTIPLICATION-CORRECTED RESULTS FOR THE FIVE NEUTRON SYSTEMS

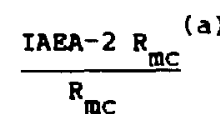

IAEA-2

$T_{C}$

\begin{tabular}{ll} 
Sample & $\mathrm{T}_{\mathrm{C}}$ \\
No. & $\left(\mathrm{s}^{-1}\right)$ \\
\hline
\end{tabular}

$1 \quad 32055$

$2 \quad 31558$

31762

29389

25485

5484

24750

23711

2324

21385

0.985

0.985

0.987

0.989

0.984

0.992

0.988

0.986

0.985

0.991

0.988

0.986

0.987

0.986

0.984

0.990

0.983

0.986

0.991

1.012

1.012

1. 012

1.014

1.015

1.020

1.013

1.020

1.018

1.023

1.018

1.019

1.020

1.017

1.013

1.017

1.023

1.016

1.021

0.987

1.017

$\pm 0.003$

0.004

$\pm 0.26$

0.36

$\operatorname{lo}(5)$
6.477

6.377

6.414

6.492

6.429

6.466

6.356

6.471

6.442

6.498

6.097

6.406

6.262

6.538

6.307

6.603

$(5.805)^{(b)}$

5.718

5.783

6.341

0.243

3.83

\begin{abstract}
$\pm 0.26$
\end{abstract}
(a) All of the multiplication-corrected rates and He are based on po values given in table XVIII.
(b) Paulty measurement with PPNCC counter onltted from average.

$2.350 \quad 1.292$

0.967

$2.345 \quad 1.287$

0.966

$2.350 \quad 1.288$

0.963

$2.330 \quad 1.280$

0.962

$2.231 \quad 1.265$

0.971

$2.316 \quad 1.240$

0.956

$2.322 \quad 1.225$

0.953

2.3251 .240

0.976

$2.310 \quad 1.220$

0.961

$2.314 \quad 1.220$

0.969

2.3321 .225

0.962

$2.309 \quad 1.184$

0.958

2.3131 .190

0.945

$2.351 \quad 1.206$

0.972

$2.330 \quad 1.173$

0.972

$2.361 \quad 1.208$

0.959

2.3241 .142

0.966

$2.340 \quad 1.163$

0.970

$2.347 \quad 1.144$

0.947

0.963

$\pm 0.008$

1.023

0.996

\section{EURATOM/}

Los Alamos

PPNCC BNFL

1.187

0.961

1.018

1.181

0.953

1.036

l. 152

0.957

1.033

1.065

1.007

1.008

1.077

0.978

1.026

1.034

0.952

1.009

1.148

0.966

1.043

1.039

0.964

1.033

1.023

0.948

1.023

1.014

1.023

1.023

1.442

1.023

1.040

1.045

0.995

1.033

0.562

0.974

1.025

0.924

1.046

1.042

1.068

1.018

1.020

0.878

$(3.087)^{(b)}$

1.030

1.022

0.807

0.979

1.025

0.774

1.067

0.016

$\pm 0.87$

$\pm 0.011$

$\pm 0.191$

0.040

0.68

$\pm 1.08$

18.7

4.06 


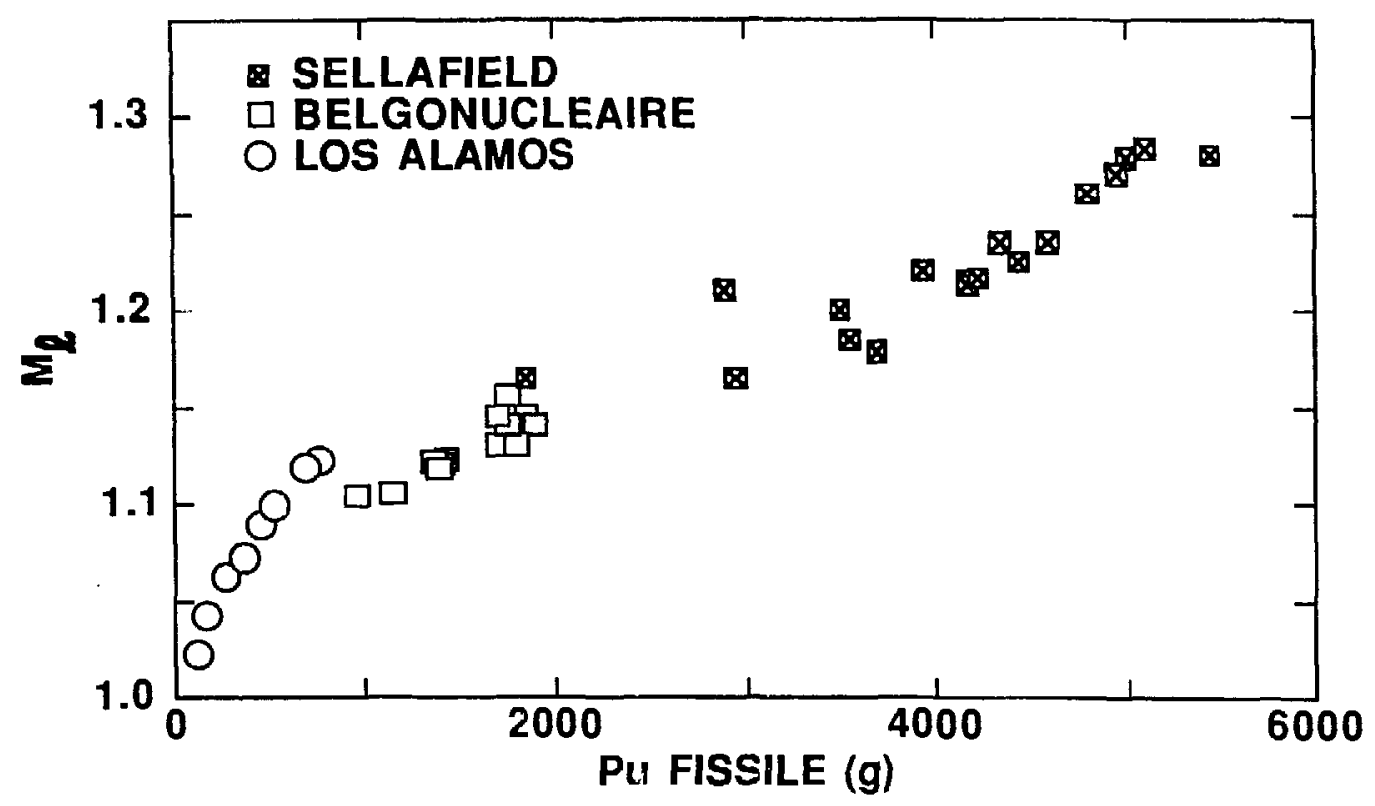

Fig. 9. The leakage multiplication, $M_{\ell}$, vs the plutonium Eissile mass for the extended data set.

approximately equal to the diameter, resulting in a maximum multiplication for that mass of material in a cylindrical shape. These relatively high $M_{Q}$ points can be seen in Fig. 9 for the Los Alamos cans with $\sim 800 \mathrm{~g}$ plutonium.

As the fill height increases in the Belgonucleaire sample, the multiplication increases slowly because there is very little neutron crosstalk or interaction between the top and bottom of the long cylinder samples. For the sellafield sample shape, the can diameter is larger than that of the Belgonucleaire cans, so the multiplication is higher for the same mass values. This can be seen in Fig. 9, where the mass values of the Belgonucleaire samples over lap the sellafield sanples.

For detectors that have accurate deadtime corrections, flat efficiency profiles, and good precisions, the calculated values of $M_{Q}$ can be directly compared with Monte carlo calculations of $M_{\ell}$. When discrepancies occur, an incorrect value of $\alpha$ is the most likely problem and the Monte Carlo $M_{\ell}$ might be used to determine a more accurate value of $\alpha$. 


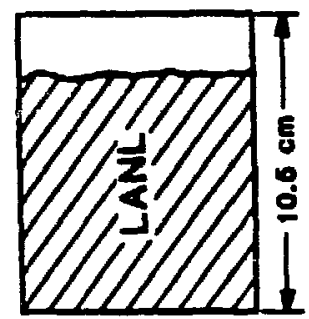

$1-8.3 \mathrm{~cm} \phi \rightarrow$

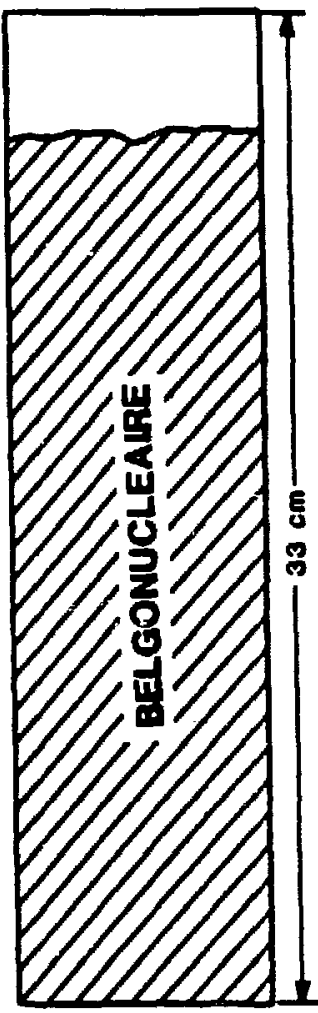

$1-8.6 \mathrm{~cm} \phi \rightarrow \mid$

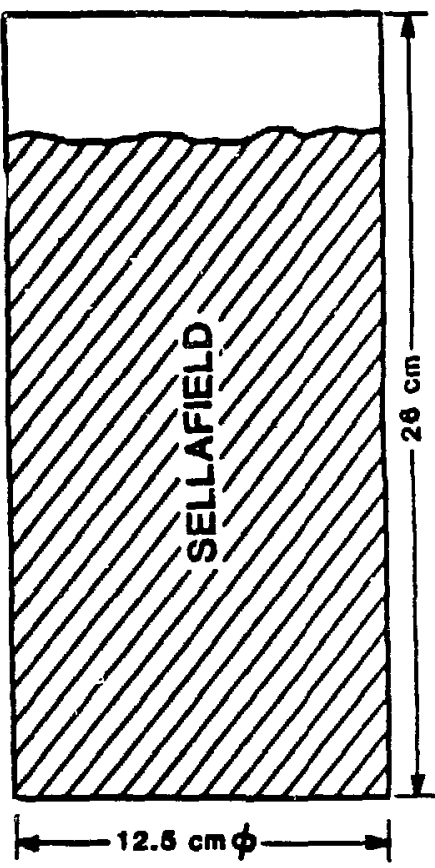

Fig. 10. The inside dimensions of the three different sample cans used in the extended sample set.

VIII. SUMMARY

Samples of $\mathrm{PuO}_{2}$ powder with mass values as high as $7.2 \mathrm{~kg}$ have been successfully measured using the five neutron counters. The deadtime corrections were adequate for the HLNC-II and BNFL systems, but some additional adjustment is needed for the PPNCC system. In general, a single constant cannot be used for $\delta$ unless the true counting rate is used in the exponential function.

The ratios of $T, R, R_{m c}$, and $M_{\ell}$ were consistent to better than 18 for the three HLNC-II systems. Table XX summarizes the expected standard deviations in the ratios compared with the observed standard deviations. Because of the good statistical precision in the data, the differences between the observed scatter (Erom all sources) and the calculated statistical standard deviation (counting statistics) give us an estimate of the nonstatistical errors, such as electronic instability, sample positioning, and background and neutron 
TABLE XX

SUMMARY OF STATISTICAL SCATTER IN THE RATIO

UITH THE IAEA-2 COUNTER

\section{Parameter}

los in $T$ ratio calc. ${ }^{a}$

Scatter in $T$ observed

$10 \%$ in $\mathrm{R}$ ratio calc. ${ }^{\mathrm{a}}$

Scatter in $R$ observed

Scatter in $\mathrm{R}_{\mathrm{mc}}$ ratio

observed

Scatter in $\left(M_{\ell}-1\right)$ ratio

observed
IAEA-2 Rat1o

\begin{tabular}{cccc}
\hline \multicolumn{5}{c}{ IAEA-2 Ratio } \\
\hline IAEA-1 & EURATOM & NMACT & BNFL \\
$(z)$ & $(z)$ & $(8)$ & $(8)$ \\
\hline
\end{tabular}

0.008

0.008

0.01

0.01

0.2

0.4

5.7

1.1

0.4

0.4

0.7

0.5

0.5

0.9

15.8

3.2

0.26

0.36

3.83

0.68

0.87

1.08

18.7

4.06

The ratio error corresponds to the average value calculated from $\sigma(T)=$ $\sqrt{T / T}$ or $\sigma(R)=\sqrt{(R+A)+A} / R$ for both IAEA-2 and the counter in question.

reflection changes. For example, with the EURATOM/Los Alamos counter the observed scatter in the coincidence is

$$
\begin{aligned}
& \sigma^{2}(\text { observed }) \simeq \sigma^{2}(\text { statistics })+\sigma^{2}(\text { geometry })+\sigma^{2}(\text { electronics })+\ldots, \\
& \left.\left.(0.9)^{2} \simeq(0.4)^{2}+\sigma^{2} \text { (geometry }\right)+\sigma^{2} \text { (electronics }\right)+\ldots .
\end{aligned}
$$


Thus, the sum of nonstatistical components is

$$
\sigma^{2}(\text { nonstatistical }) \simeq(0.9)^{2}-(0.4)^{2}
$$

$$
\sigma(\text { nonstatistical }) \simeq 0.88
$$

This value is smaller (0.4\%) for the IAEA-l counter.

The calibration curve (EURATOM/Los Alamos) showed an average absolute mass residual of $2.96 \%$ for the data before multiplication corrections and $1.28 \%$ after multiplication corrections. If the three outliers are included in the data, the average residuals get a little bigger, but not much because of the large number of samples.

A single constant slope for $R_{m c}$ was found adequate to fit the entire range of masses from 60 to $7200 \mathrm{~g}$ of $\mathrm{PuO}_{2}$ for the HLNC-II systems. This slope gives a baseline ( $s$ lope $\simeq 18.17$ for EURATOM/Los Alamos), and all outliers ( $\mathrm{R}_{\mathrm{mc}}$ ) fell above this line. Outliers from high molsture or impurity content will fall above the $R_{m c}$ baseline and the ratio $R_{m c} / g$ can be used to identify outliers.

Concerning equipment reliability, five NDA systems were shipped to sellafield for this exercise and two were home based (BNFL). All of the equipment arrived at sellafield in good working order, and no repair, maintenance, or replacement was required during the 5-day exercise.

Although the equipment was shut off each night because of plant safety regulations and restarted the next day, the good precisions quoted in Table $\mathrm{XX}$ were nonetheless achieved.

Measurements repeated a few days apart on the same samples ( 9 and 10 ) in the IAEA-2 counter gave good agreement, with an average difference of only 0.28 for the two sets of measurements. The exercise showed that achieving excellent precision is possible using the neutron counting systems under field operating conditions. 


\section{ACKNOWLEDGMENTS}

We are grateful for the assistance provided by BNFL at Risley and Sellafield in coordinating the exercise, setting up equipment, providing samples, and health-physics support. Their excellent cooperation in this calibration and evaluation work was appreciated very much. We hope the ability to verify and measure high-mass plutonium samples will be improved by this work.

\section{REFERENCES}

1. H. O. Menlove and J. E. Swansen, "A High-Performance Neutron Time-Correlation Counter," Nucl. Technol. 71, 497-505 (November 1985).

2. M. S. Krick, Los Alamos National Laboratory, provided, as a private communication, the CAL4 program for the HP-85 minicomputer.

3. M. S. Krick and H. O. Menlove, "The High-Level Neutron Coincidence Counter (HLNCC): Users' Manual," Los Alamos Scientific Laboratory report LA-7779-M (ISPO-53) (June 1979).

4. F. J. G. Rodgers, British Nuclear Fuels at Sellafield, United Kingdom, report NMACT (85) (1985).

5. John Lightfoot, British Nuclear Fuels at Sellafield, United Kingdom, private communication, February 1985.

6. B. G. R. Smith, H. O. Menlove, M. S. Krick, and R. Ingels, "Field Test and Calibration of the HLNCC-II for High Burn-up Plutonium samples," in 7 th ESARDA Annual Symposium on Safequards and Nuclear Material Management, (Liege, Belgium, 1985), L. Stanchi, Ed., Joint Research Center, Ispra, Italy (Vol. 19), Pp. 177-183.

7. K. Böhnel, "The Effect of Multiplication on the Quantitative Determination of Spontaneously Fissioning Isotopes by Neutron Correlation Analysis," Nucl. Scl. Eng. 90, 75-82 (1985).

8. N. Ensslin, "A Simple Self-Multiplication Correction for In-Plant Use," in 7th ESARDA Annual Symposium on Safequards and Nuclear Material Management, (Liege, Belgium, 1985), L. Stanchi, Ed., Joint Research Center, Ispra, Italy (Vol. 19), pp. 223-238. 